\title{
Observational Spatial Memory in North Island Robins (Petroica longipes)
}

\author{
Nicola Ellen Armstrong
}

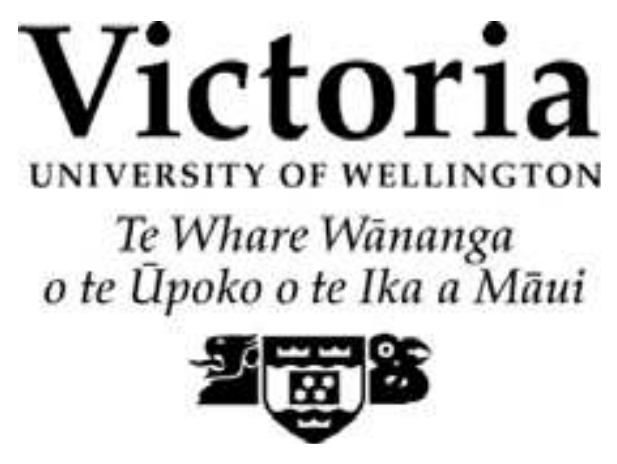

2012

A thesis submitted in partial fulfilment of the requirements for the degree of Master of Science in Ecology and Biodiversity. 



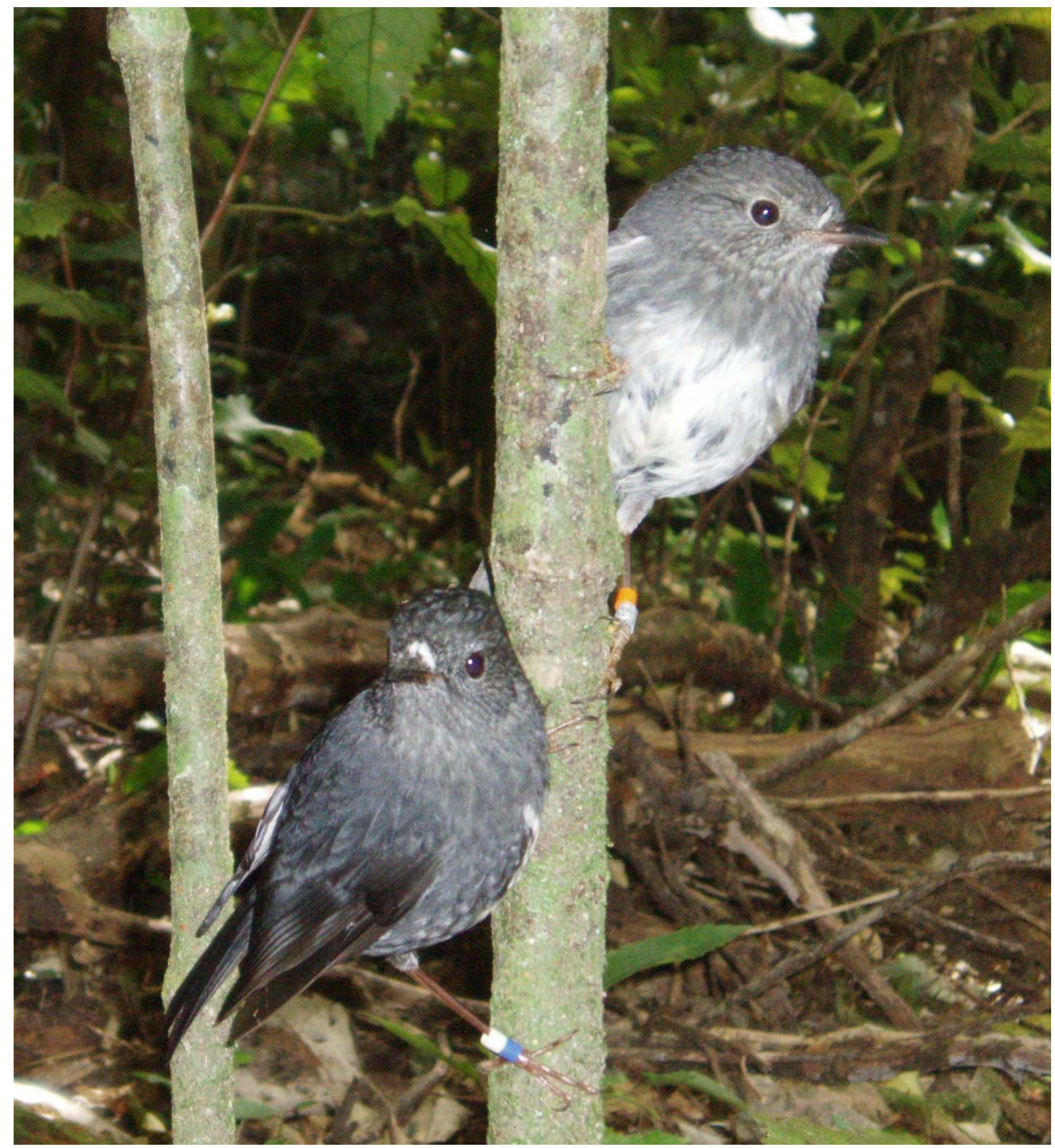

Figure 1: North Island robin (Petroica longipes). Showing plumage sexual dimorphism: female (top) and male (bottom) 


\section{Abstract}

Observational spatial memory is employed by members of food-hoarding species to pilfer caches created by other individuals more effectively. North Island robins (Petroica australis) experience high levels of reciprocal cache pilferage within mate pairs. These circumstances were hypothesised to produce conditions under which advanced pilferage strategies such as observational spatial memory may evolve. Here I tested the ability of North Island robins to use observational spatial memory to discriminate between varying prey rewards. Three experiments were conducted which differed in the maximum number of prey items offered as a reward. Additional variables of retention interval, number of cache sites and a variable reward were included to assess how the birds' memory was affected by small-scale factors. Results showed that North Island robins performed above chance expectations in most treatment combinations, indicating that they were able to utilize observational spatial memory. They were equally able to discriminate between different combinations of prey numbers that were hidden in 2, 3 and 4 caches sites from between 0, 10 and 60 seconds. Overall results indicate that North Island robins can solve complex numerical problems involving more than two parameters and up to one minute long retention intervals without training. 


\section{Acknowledgements}

I wish to thank both my supervisors, Dr K.C. Burns and Dr Jason Low for their suggestions, comments and feedback throughout this process, as well as for providing the initial suggestions which allowed this project to develop.

I would also like to express my gratitude to Zealandia for allowing me access to their wonderful facility. The staff were always helpful whenever I had queries and their willingness to stop and chat made many cold winter mornings much more pleasant. The good people at Rata cafe with their regular injections of caffeine also helped me through my field work.

Finally I would like to thank my family for their enthusiasm, their advice and their constant support of my studies.

This work was made possible through the Dominion Post Masters by Thesis scholarship. 


\section{Table of Contents}

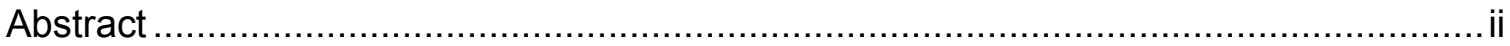

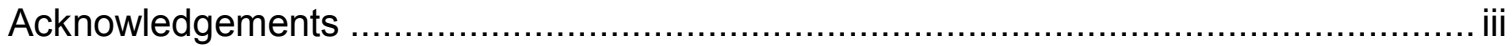

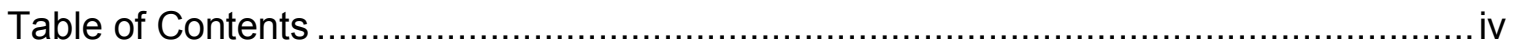

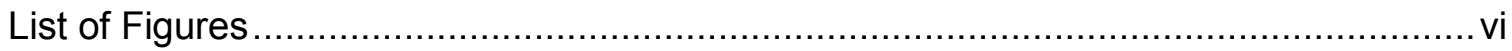

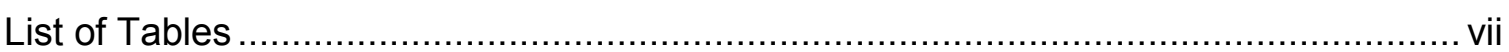

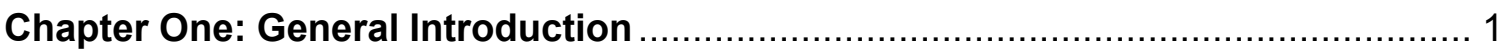

Food Hoarding Behaviour in Birds .................................................... 1

Memory in Food Hoarding ................................................................ 2

Observational Spatial Memory …........................................................... 4

Components of Observational Spatial Memory...................................... 8

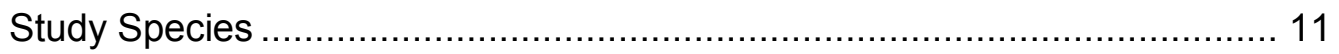

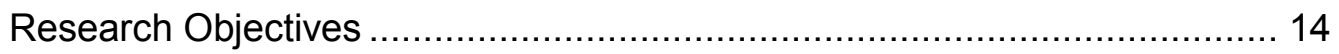

Chapter Two: Observational Spatial Memory in North Island Robins ................. 15

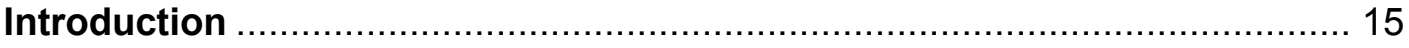

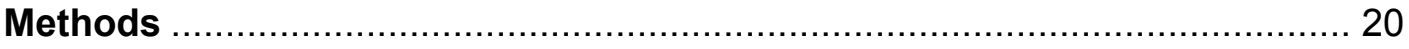

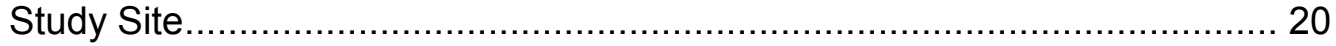

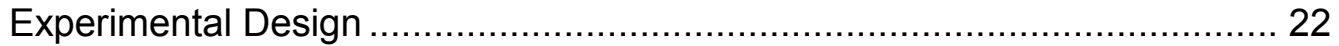

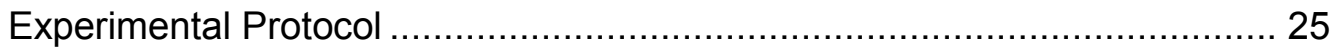

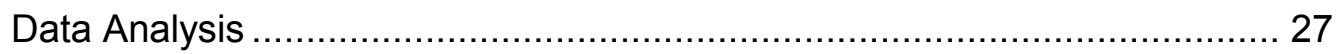

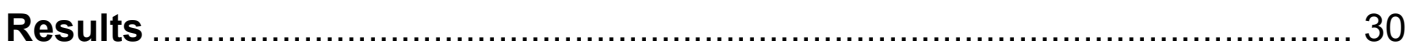

Non-random Decision Making for Larger Numbers of Prey....................... 30

Numerical Discrimination between Variable Rewards.............................. 40

Analysis of Independent Variables ................................................... 43

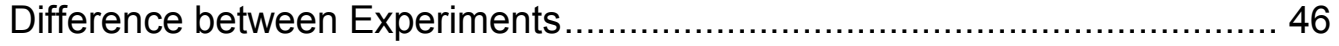

Additional Variables.................................................................... 47

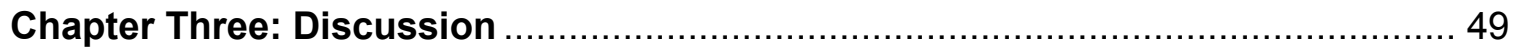

Observational Spatial Memory in North Island Robins ............................ 49

Number of Cache Sites .............................................................. 52

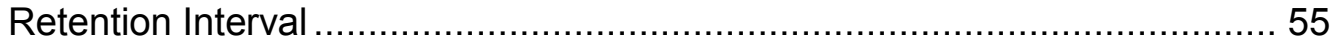




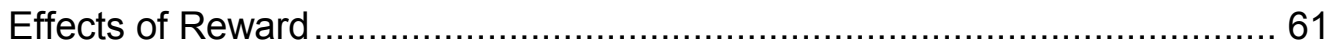

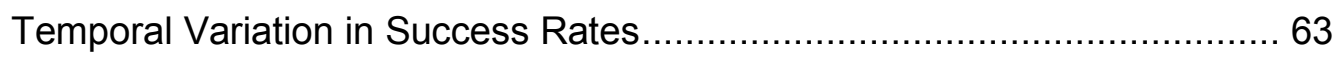

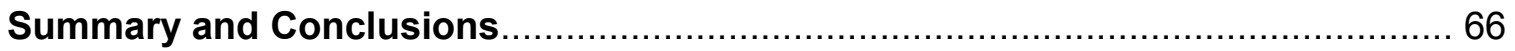

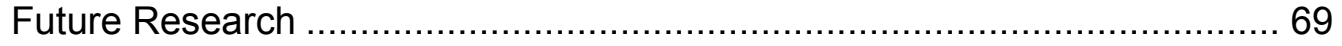

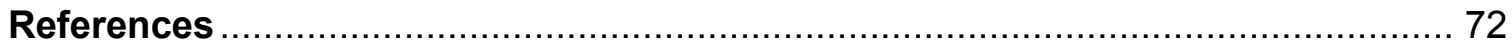




\section{List of Figures}

Figure 1: North Island robin (Petroica longipes) ....................................................

Figure 2: Map of Zealandia showing locations and approximate territories of the ten birds used in this study.

Figure 3: A North Island robin investigating the contents of an artificial cache site during an experimental trial.

Figure 4: Success rate minus the success rate predicted by chance for the three experiments

Figure 5: Success rate for each combination of experimental variables for the three experiments..

Figure 6: Success rate minus chance for each combination of experimental variables for the three experiment.

Figure 7: Percentage of successes across all trials by individual bird 46

Figure 8: Percentage of 'correct' choices across all trials over the sample period 48 


\section{List of Tables}

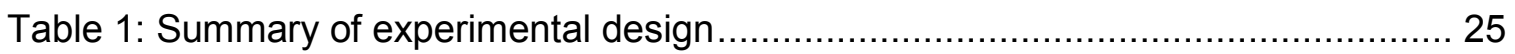

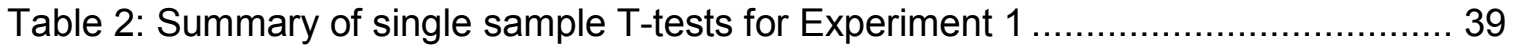

Table 3: Summary of single sample T-tests for Experiment 2 ................................ 39

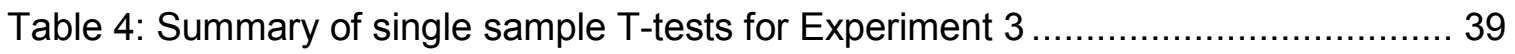

Table 5: Single sample T-test analysis of all nine possible combinations of variables across Experiments 1-3 ................................................................ 42

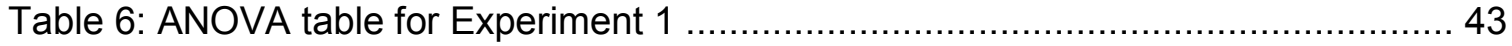

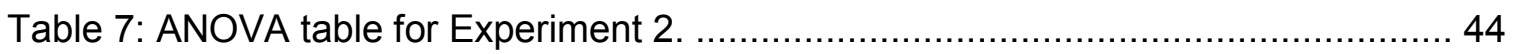

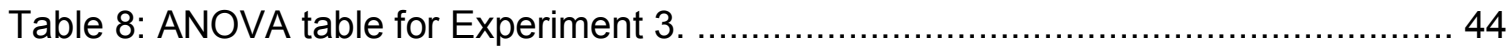

Table 9: ANOVA summary for the three experiments excluding Individual as a random factor. 45 


\section{Chapter One}

\section{General Introduction}

\section{Food Hoarding Behaviour in Birds}

Most species are exposed to environments where resource availability varies both spatially and temporally. Additionally this is often matched by daily and seasonal fluctuations in an individual's energy demands. As a result many animals will be faced with periods of high resource abundance which must be exploited in order to reduce the costs associated with periods of low abundance or high energy demand (Vander Wall 1990). When dealing with a surplus of food there are two major strategies which can be employed (Gerber et al. 2004). The first is to consume the items and store the excess energy as fat. Consumption prevents food from being lost to competitors and is a common strategy for many mammalian species, which lay down stores of subcutaneous fat that can be metabolized to meet energy requirements during lean periods. This approach has a drawback in that large fat reserves can hinder movement and increase mass-dependent predation (Macleod et al. 2005; Witter et al. 1994). This is especially problematic for birds, as flight imposes physiological restrictions on the amount of weight an individual can carry. An alternative strategy is to store excess food externally for later consumption. This is called food caching or hoarding (the two terms are synonymous) and is widely demonstrated among a variety of bird taxa.

Two major food hoarding strategies are employed. One strategy is larder hoarding, where

all food items are stored at one or a few central sites. This approach is only useful if the animal is able to rigorously defend its stores from cache thieves. The loss of the larder can be critical, especially if the stored food represents an entire winters resources. Larder hoarding is employed by various species of woodpecker (Hay 1887; MacRoberts 1975; Stacey 1981), some raptors (Collopy 1977; Holthuijzen 1990; Korpimaki 1987; Suhonen et al. 2007), many mammalian species (see Vander Wall 1990 for a full review) and some 
insects (notably eusocial bees: Rinderer \& Baxter 1979; Rinderer et al. 1982). However the most common caching method among birds is scatter hoarding, where food items are stored in multiple locations called caches. This reduces the overall impact of cache pilfering, as a thief is unlikely to locate all available caches meaning that catastrophic loss of stored food resources is unlikely to occur. Avian species which utilize this strategy include some of the most prolific hoarders such as the Corvidae (crows, jays, ravens, nutcrackers) and Paridae (tits and chickadees), some species of which are known to store well in excess of 10, 000 items in a year (see Brodin 2010).

\section{Memory in Food Hoarding}

Food hoarding is often a biologically expensive activity. Once a food item is located an individual must expend energy in manipulating, transporting and caching the item. This also incurs a foraging-time expense and the time taken for caching must be weighed against the benefit gained from the stored food (McNamara et al. 1990; Wood 1993). In order for food hoarding to be an evolutionarily adaptive trait the caching individual must have a better chance of recovering it's cache than another conspecific (Andersson \& Krebs 1978; Smith \& Reichman 1984).

For species which scatter hoard, accurate memories for cache locations would provide an enormous recovery advantage. This is not strictly necessary as an individual may simply create caches in locations where they prefer to forage, always cache near specific landmark types, or rely on external cues such as smell (Brodin 2005). This means they do not need to remember exact locations as they are likely to recover their caches during normal foraging activity or by always searching for caches near their preferred landmark type. It was initially thought to be unlikely that scatter-hoarders possessed sufficient memory capacity to accurately remember the large numbers of individual caches they often created (Kamil \& Gould 2008). However it has now been demonstrated that memory is indeed important in cache recovery and almost all scatter-hoarding species appear to accurately remember the locations of caches that they have made (Kamil \& 
Balda 1985; Sherry et al. 1981; Tomback 1980; Vander Wall 1982).

Spatial memory is an animal's ability to record and recall locations and spatial landmarks within a given area. This is a vital function for most species as spatial components are involved in many ecologically important behaviours where it is necessary for an individual to retain an accurate representation of where they are, what locations they have been to and where they are able to go from that location. These behaviours include dispersal, migration, territoriality, predator avoidance, mate search and importantly food storage (Sherry 1998). In one-trial associative memory tasks involving feeder arrays, marsh tits (Parus palustris) and jays (Garrulus glandarius), both food-storing species, returned to the correct spatial location rather than the feeder with the correct object specific cues. This was compared to blue tits ( $P$. caeruleus) and jackdaws (Corvus monedula), non-storing species, which returned equally often to both the feeder at the correct spatial location and the feeder with the correct object specific cues (Clayton \& Krebs 1994).

Like any adaptive function, species which rely heavily on spatial memory for survival would be expected to have highly developed abilities in this area. This is often referred to as the ecological hypothesis (Shettleworth \& Hampton 1998) and in almost all cases food-storing species outperform closely related non-storing species on spatial memory tasks. This suggests that food-hoarding species have evolved adaptive cognitive specializations related to their need to recall large numbers of spatial coordinates. Balda and Kamil (1989) and Bednekoff et al. (1997) compared a number of food-hoarding Corvid species while Pravosudov and Clayton (2002) studied two groups of black-capped chickadees which differed in their dependence on cached food for winter survival. As predicted under the ecological hypothesis species with higher levels of cache dependence out-performed less proficient cachers both for accuracy and speed of recovery. 


\section{Observational Spatial Memory}

The energy costs associated with food hoarding mean that it is not surprising that some individuals adopt a 'cheat' strategy by pilfering caches made by others. There are mixed hypotheses in this area, with some suggesting that this should especially be the case for subordinate individuals who may not be able to successfully compete directly for food with more dominant individuals (Lundborg \& Brodin 2003). Others predict than dominant individuals should devote more time to pilfering than foraging as they can easily displace subordinates from their cache sites (Brodin et al. 2001). The result of the obvious incentive to steal is that strategies have evolved which allow individuals to conduct more accurate cache theft. After observing a conspecific caching, a pilferer can attempt to immediately steal or recache the food items. This is potentially dangerous however as the owner of the cache is likely to still be in the vicinity and may react aggressively if the thief is discovered. Because of this a less risky method is to observe and remember the location of a cache site and to return later when the owner is less likely to be around. This form of memory is referred to as observational spatial memory (OSM) and has been identified as an important and advantageous cognitive ability for food pilfering. The ability to employ OSM when stealing cached food from others reduces the incidence of potentially dangerous aggressive encounters and may provide a means for subordinate individuals to compete indirectly for food without the need to physically displace dominant individuals.

Many species, both avian and mammalian, possess excellent spatial memory. However this does not necessarily translate to good observational spatial memory. Black-capped chickadees (Parus atricapillus) have been widely used in studies on spatial memory in food hoarding (reviewed in Shettleworth 1990). In laboratory settings chickadees show high accuracy in recovery for their own caches up to 28 days later (Hitchcock \& Sherry 1990) and use spatial memory in order to locate the caches (Baker et al. 1988; Sherry 1984). Despite this, Baker (1988) found that black-capped chickadees showed no recovery benefit from observing another individual caching compared to recovering 
caches made in its absence. This was true both for long delay times of 2 hours and shorter delays of 6 minutes. Hitchcock and Sherry (1995) also confirmed that chickadees do not display OSM, however they did note that $5 \%$ of caches were pilfered immediately after being hidden. This suggests that cache theft does occur, but only at low frequency and does not seem to involve long term memory. Shettleworth \& Krebs (1986) demonstrated that the act of placing a seed at a cache site was not essential for accurate recovery by chickadees indicating that it is not the act of caching itself which results in memories being created.

Caching behaviour seems to develop innately in those species which hoard food (Clayton $1992 ; 1994 ; 1996)$ without the need to learn directly from an adult. Despite this caching can vary substantially, both in terms of quantity and individual ability. Caching behaviour often requires a degree of experience in order to learn what are appropriate items to cache, selection of correct caching locations and to develop accurate retrieval skills (Clayton 1994; 1995). New Zealand robins do not have a long developmental period and are usually excluded from the natal territory within a month or so of fledging (Armstrong et al. 2002). This means that young robins do not have a protracted parental learning period during which to develop caching and pilfering behaviours. Caching may develop innately but there is likely to be a large amount of learning associated with choosing adequate cache sites as well as gaining experience both as a thief and in cache protection from pilfering (Emery \& Clayton 2001). It is also possible that a reduced learning period could result in increased learning proficiency in order to maximise skills gained in this short time frames. However reduced caching by parents over the breeding season (due to surplus resources being committed to rearing offspring), combined with the short parental learning period suggests that juvenile robins most likely develop their pilfering skills once they leave their parents territories and form pairs later in their hatch year (Powlesland 1997). Marsh tits (P. palustris) begin storing after feeding independence, suggesting that this behaviour is not learnt from observing adults. Over the initial period of caching onset the appropriateness of items chosen to be stored and the choice of cache 
location improves, suggesting that experience does play some role in the development of full caching behaviour (Clayton 1992).

Bednekoff \& Balda (1996b) initially suggested that observational spatial memory "could have evolved either as a consequence of extreme cache dependence, as a consequence of caching in flocks, or may have required the combination of these traits." Follow-up studies by Bednekoff \& Balda (1996a) compared Clark's nutcrackers (Nucifraga columbiana) and Mexican jays (Aphelocoma ultramarine). Clark's Nutcrackers are caching specialists and have accurate spatial memory for their own cache sites. Mexican jays cache at low levels but have no specialised adaptations to facilitate caching and do not appear to be highly dependent on cached food. Clark's nutcrackers live alone or in pairs while Mexican jays form flocks numbering several dozen. Both species were able to recover caches that they had observed another individual of the same species make. Bednekoff and Balda concluded that enhanced spatial memory and social living are not both requisites for the evolution of observational spatial memory. Despite this, Mexican jays were better at recovering observed caches than nutcrackers, suggesting that close attention to the actions of others, arising from social living, may affect the degree to which OSM develops. This is not entirely surprising, as the increased social pressure of living in large groups creates ideal conditions for food pilfering to occur. As a result the conditions for adaptive food hoarding are probably more stringent for social than for solitary animals (Bednekoff \& Balda 1996b).

A similar study by Scheid and Bugnyar (2008) compared social foraging, low-frequency caching jackdaws with less social but more caching specialised ravens. Ravens not only preformed better at locating caches than jackdaws but also had fewer recovery errors, returning to caches that had already been emptied less often than jackdaws. Compared to this jackdaws preformed no better than chance at locating baited cache sites and had a less accurate search pattern, returning to caches which they had already checked more often than Ravens. In this instance the less social, but more cache-dependent species preformed better than the socially cohesive species which only caches at low densities. 
This study however failed to take into account the possibility that a variable social structure may be more conducive to 'cheating' than permanent social groups. Individuals in a stable social group who are regularly caught pilfering may be shunned or attacked by other members of the flock. In this case social groups may offer more opportunities for pilfering but group dynamics may prevent this behaviour from becoming widespread. This study contrasts with that of Bednekoff and Balda (1996a) and suggests that overall OSM is somewhat species specific and may be controlled by a number of ecological and cognitive traits, of which sociality and food-hoarding intensity are only two factors, albeit likely to be important ones. Jackdaws are mainly insectivorous and cache only small amounts and they also seem to lack some of the behavioural elements associated with caching such as covering hidden objects with substrate (See Scheid \& Bugnyar 2008).

New Zealand robins are similar to jackdaws in that they cache high-value insect prey in low quantities and do not attempt to cover or hide their caches in any way. Robins are not highly cache dependent and rely on caching as an external mechanism for dealing with short-term temporal resource fluctuations (Menzies \& Burns 2008). When they do cache, North Island robins tend to maintain only a few active cache sites at any one time and will also reuse the same locations during subsequent caching bouts (Alexander et al. 2005). However unlike jackdaws robins are not social or flock foragers and are strictly monogamous (Taylor et al. 2008), spending most of their lives in mate-pairs. Experience in pilfering and having caches pilfered is likely to be important for an understanding of cache protection and successful pilfering techniques to develop (Emery \& Clayton 2001). Because robins are the only New Zealand species known to regularly cache, and because of their low levels of sociality, there would seem to be minimal opportunity to gain experience in this area. However once a bird has gained a mate and a pair is established there will more opportunities to both observe caching behaviour by another individual and to gain experience in pilfering those caches. Intra-pair pilfering may be easier due to familiarity with the other individual gained through long-term cohabitation. This could result from increased familiarity with the other's caching behaviour, preferred caching sites and behaviour towards its mate in pilfering situations. Pilfering from mates may also 
be less dangerous as retaliation by the owner of the cache would be expected to be less aggressive. Injuring ones mate is largely non-adaptive as it would lower their fitness, and hence their ability to contribute to breeding and raising offspring. This is especially true in strictly monogamous species like robins where finding a new mate and establishing a pair-bond is likely to require more investment than maintaining an existing bond.

\section{Components of Observational Spatial Memory}

While observational spatial memory may appear superficially to be a simple memory task, it in fact involves several complex cognitive processes. Not only must the observing bird accurately note the spatial and landmark cues surrounding the cache site, they must do so from a distance. Experiments have shown that the act of storing or travelling to a cache site is not necessary to remember the cache location (Baker et al. 1988; Shettleworth \& Krebs 1986). Some work with Clark's nutcrackers suggests that they may use a view-matching technique to locate the 'snapshot' which corresponds with what they saw during caching (Kamil et al. 1999). This would be inefficient for recalling large numbers of cache locations (Emery 2006), but may require less specialised cognitive abilities than other methods. It is possible that robins may use this, as they are only required to remember small number of locations. However this may be less effective for OSM, as the watching bird is not in a position to make a 'snapshot' of the exact cache location. This would be a viable method for pilfering if the thief initially returned to the original site where it had observed the caching and then proceeded to the 'snapshot' from there. van Horik and Burns (2007) noted that when returning to pilfer or recover a cache, robins generally flew directly to the cache location, without returning to their initial view point. Bednekoff and Balda (1996b) also showed that view-matching is not an essential memory technique for cache recovery in pinyon jays, as during pilfering they moved from one cache site to another without needing to return to the location from where they had observed the caching act. However Watanabe and Clayton (2007) showed that scrubjays are more accurate at recovering others' caches if they have the opportunity to 
observe the caching event from the same viewing direction as the caching bird. This suggests that while view matching may not be essential for locating others caches through OSM, recovery accuracy is increased when less mental rotation is required. A further alternative is that a bird may use visual landmark or spatial cues in order to recover hidden caches.

All avian species studied to date have been shown to utilize landmarks to some extent for accurate cache recovery (Bossema 1979; Gould-Beierle \& Kamil 1998; Vander Wall 1982). When trained to find a target location using an array of nine landmarks, Clark's nutcrackers were able to find the target accurately using any subset of three of the original landmarks (Basil 1993 in; Kamil et al. 2001). This suggests that the birds rely on multiple cues to locate a site and that these can be integrated in a variety of ways. When local landmarks in a small caching arena are removed, Clark's nutcrackers show a decline in recovery accuracy compared to control treatments (Balda \& Turek 1984). Vander Wall (1982) also used nutcrackers and demonstrated that when landmarks within their aviary were displaced the bird's recovery attempts shifted in the direction of the displacement. Bossema (1979) found that Eurasian jays caches more near vertical objects than horizontal objects and showed greater retrieval accuracy in cache retrieval when these vertical cues were present.

There is some debate as to whether local (proximal) or global (distal) cues are more important. Herz et al (1994) showed that black-capped chickadees were significantly less accurate in relocating their own caches when distal landmarks were removed. Removal of proximal landmarks had no significant effect on the accuracy of recovery in this species. Despite this, other studies have used artificial proximal landmarks to delineate cache locations and still shown high levels of cache retrieval (Clayton \& Dickinson 1998; Dally et al. 2005). Landmark use has not been studied in robins; however being small passerines it is possible that they behave in a similar fashion to chickadees.

Accurate observation of the location of a cache site is a vital component of OSM but may 
not be the only element which a pilferer should take into account. Identification of the type of items being stored as well as the number of items in each cache site may be important in prioritising when and which caches to pilfer. Highly perishable items should be pilfered within a short period of observing them being cached as they are more likely to be recovered by the storer after only a shorter interval due to the likelihood of decay. Additionally caches which contain more items should be prioritised over caches containing fewer items as this would maximise the energy gained from each pilfering event.

Numerical processing has been demonstrated in a wide range of animal species (Agrillo et al. 2007; Rumbaugh et al. 1987; Uller et al. 2003). When distinguishing between sets of items, number discriminations can be expressed in several ways. This can be as the total number of stored items, as the ratio between the two sets, or as the numerical distance between numbers (Brannon 2005; Emmerton 2001). Additionally there appears to be two different systems utilized when dealing with numerical computations. Small numbers of less than four are dealt with innately by most non-human species (Feigenson et al. 2004; Hauser et al. 2000). Larger number discriminations have been shown in some highly trained lab animals (Beran 2001; Pepperberg 2006; Tomonaga 2008), but also appear to be displayed naturally to some extent by wild animals in the absence of training (Hunt et al. 2008; Low et al. 2009; Lyon 2003; White et al. 2009).

The food hoarding paradigm provides an interesting area in which to investigate the abilities of non-human animals to display numerical competency. Food hoarding behaviour requires that an individual be able to track not only the number of cache sites which it currently has, but also additional factors such as the number of items in each site, whether some or all of those items have been retrieved and in some cases how long the items have been cached for. These cognitive requirements provide ideal conditions for advanced numerical abilities to develop. North Island robins have been shown to possess an excellent innate numerical sense (Hunt et al. 2008). Not only can they accurately discriminate between hidden caches containing up to 12 prey items, but in violation of 
expectancy trials they also searched for significantly longer when they were allowed to retrieve only a portion of the prey items they had seen hidden. This indicates that robins are capable of using sophisticated numerical representations when dealing with stored food items and provides and interesting glimpse into the cognitive processes which are involved in food hoarding behaviour.

\section{Study Species}

The study described here was conducted with a population of North Island Robins (Petroica longipes) located at Zealandia (formerly Karori Wildlife Sanctuary) in Wellington, New Zealand. The North Island robin is a small passerine endemic to New Zealand. Prior to 2006 North Island robins were considered a subspecies of the New Zealand robin (Petroica australis). However morphological (Holdaway et al. 2001) and new molecular evidence (Miller \& Lambert 2006) provides a strong basis to suggest the North Island robins should be considered a separated species, with the South Island (Petroica australis australis) and Stewart Island robins (Petroica australis rakiura) regard as subspecies. Despite their name New Zealand robin species are not closely related to the European robin (family: Muscicapidae) or the American robin (family: Turdidae). Instead they belong to the family Petroicidae, a group of roughly 45 species of insectivorous birds found throughout Australasia and the Western Pacific region.

North Island robins are morphologically sexually dimorphic with males having darker dorsal plumage than females (Fig.1). Males however display delayed plumage maturation, with birds becoming sexually mature by their first year but not undergoing their final adult moult until after their first breeding season (Armstrong 2001; Powlesland 1997). This can result in misidentification of juvenile males as female, although this is easily resolved once the birds begin to sing and display breeding behaviour. Due to the isolated nature of New Zealand and the historic lack of mammalian predators, New Zealand robins are naive and lack pronounced anti-predatory behaviours. Because of this, wild individuals will fearlessly approach researchers in the field and accept food offered 
by hand allowing experiments to be conducted in situ (Powlesland 1997). Additionally robins are monogamous (Taylor et al. 2008) and pairs will defend an exclusive territory year-round allowing the same individuals to be located consistently. Over winter this territory may be further subdivided between the pair as they forage more independently, however the total territory boundary will still be defended by both individuals. Perhaps most importantly New Zealand robins are known to scatter-hoard food items (Alexander et al. 2005; Powlesland 1980; Steer 2006), and it is this behavioural trait which has been used to study memory ability in a wide variety of species (see Brodin 2010, for a recent review).

The majority of food caching studies have been conducted on Northern Hemisphere species. Northern Hemisphere winters are characterised by low temperatures and in many places heavy snow fall. Additionally many Northern forest types are deciduous and so food resources may become scarce over the winter. Conversely the Southern Hemisphere is more temperate and winter conditions are generally milder with high rainfall but usually only light snowfall. Most New Zealand forests are evergreen and remain relatively productive all year round. This milder climate also provides favourable conditions for many invertebrates to overwinter successfully, meaning that insectivorous species are not as constrained by winter food demands as their Northern counterparts. These factors combine to reduce the evolutionary incentive to hoard food, a behaviour which is biologically costly and requires advanced cognitive behaviours in order to be successful. As a result New Zealand robins are one of only a few Southern Hemisphere species which are known to cache food (see Vander Wall 1990). New Zealand Robins are not likely to be related to a caching ancestor, although it seems probable that caching behaviour first evolved in the ancestor of both the North Island ( $P$. longipes) and the South Island ( $P$. australis spp.) robins as the behaviour is prevalent in both species. Closely related New Zealand species, tomtits (Petroica macrocephala) and black robins (Petroica traversi), as well as other Australasian Petroica species, have not been reported to cache. 
The fact that robins do cache food is probably a result of their access to large prey items. New Zealand robins are known to prey on some of the world's largest invertebrates (Powlesland 1980), such as tree weta (Hemideina spp.) and native giant earthworms (Lumbricidae). Prey of this size provides more food than can be consumed in one sitting and so is usually dismembered and any excess items are cached for later consumption. In this way robins are perhaps more analogous to birds such as raptors or mammalian carnivores like leopards which will store large kills for consumption over a period or hours or days (Menzies \& Burns 2008).

While many Northern Hemisphere species may create thousands or even tens of thousands of caches and rely heavily on this stored food for winter survival, robins need only store food when it is immediately abundant. This results in far fewer caches being created at any one time and turnover of cached food items is over a much shorter period. Powlesland (1980) found that South Island (P. australis) robins cache only invertebrates, although they were observed eating both invertebrates and berries. Of all cached prey $70 \%$ were earthworms and $58 \%$ of all food items were recovered on the same day, with all items being removed (either recovered or pilfered) within three days. North Island robins caching behaviour appears to be very similar, although North Island robins will utilise the same cache site to hide multiple prey items (Alexander et al. 2005), something which South Island robins rarely do. Most commonly used cache sites are branch-trunk axils, depressions in branches and tree fern fronds, and no attempt is made to conceal cached items.

Recently robins have been used to study not only caching behaviour (Alexander et al. 2005; Steer \& van Horik 2006; Steer 2006) but also social aspects such as the effects of sex and social dominance on food hoarding behaviour (Burns 2009; Burns \& Steer 2006; Burns \& van Horik 2007; Steer \& Burns 2008) and numerical competency within the food hoarding paradigm (Hunt et al. 2008). 


\section{Research Objectives}

My research was undertaken with the intention of looking not only for the presence of observational spatial memory of memory in robins but also to quantify how the accuracy of this memory was affected by various small-scale factors. It is well know that memory traces decay over time and so three retention intervals of zero, ten and sixty seconds between observing a caching event and retrieval of the food items was one of the independent variables. The second variable was the number of artificial cache sites in each trial, which ranged from 2 to 4 , creating differing levels of complexity in retrieval of the hidden prey. Previous work has shown that robins possess excellent number sense (Hunt et al. 2008), and this was incorporated into the study through three experiments which differed in the number of prey offered as a reward. As an additional element, a variable reward was offered in which the birds were offered a choice between a large reward and a smaller one. I hypothesised that robins would be capable of accurate retrieval across all trials (i.e. able to display OSM), but that memory accuracy would decrease with both increasing retention interval and increasing number of cache sites. Additionally I hypothesised that retrieval accuracy would be highest when the birds were not presented with a variable reward, as this would not require discrimination between two separate sites.

Chapter Two outlines the experimental protocol used in this study as well as the findings relating to the birds accuracy in locating experimentally hidden prey. The importance of each of the independent variables as a predictor of success is also addressed, as well as a variety of environmental variables surrounding the trials. Chapter Three summarises these results and discusses the findings of this study in regards to the ecological history of the North Island robins and a comparison of how this study's findings relate to the current literature in this area. 


\section{Chapter Two}

\section{Observational Spatial Memory in North Island Robins}

\section{Introduction}

Many animal species hoard food (Vander Wall 1990), suggesting that it must convey a significant survival advantage. While food hoarding has been widely studied, early research in this area consisted mainly of ethological descriptions and theoretical models of hoarding behaviour (See Brodin 2010 for a review). Current research seeks to address both the evolutionary pressures as well as the underlying cognitive mechanisms required for successful cache storage and retrieval.

Observational spatial memory (OSM) refers to an individual's ability to observe the caching behaviour of a conspecific and to encode the information regarding those cache locations made by others (Bednekoff \& Balda 1996b; a). This information can then be employed at a later date to pilfer or recache the food items belonging to the other individual. In this regard OSM tends to be applied exclusively to species which hoard food, although it shares elements with other observational learning and memory tasks.

Early spatial memory studies found no evidence that birds were able to accurately locate caches that they had seen others making (Vander Wall 1982; Baker et al. 1988). However Bednekoff and Balda (1996b) conducted a series of experiments with Pinyon jays (Gymnorhinus cyanocephalus) which clearly showed that observing birds were able to recover caches made by others with significantly less errors than if they were searching randomly. Since then OSM has been demonstrated to various degrees in a number of other corvid species such as Mexican jays (Aphelocoma ultramarine), Clark's nutcrackers (Nucifraga columbiana), scrub-jays (Aphelocoma coerulescens), jackdaws (Corvus 
monedula) and ravens (Corvus corax); (Bednekoff \& Balda 1996a; Bednekoff et al. 1997; Bugnyar \& Kotrschal 2002; Scheid \& Bugnyar 2008).

Traditionally animals, and especially birds, have been used as models of only simple associative behaviour. The growing area of comparative cognition has advanced our understanding of the mental capabilities of non-human animals (Emery 2006; Emery \& Clayton 2004; Emery \& Clayton 2009). Advanced cognitive traits such as theory of mind, episodic-like memory, numerical skills and future planning have all been demonstrated in a growing variety of avian species (Clayton \& Dickinson 1998; Brannon 2005; Dally et al. 2010; Emmerton 2001).

Currently OSM has only been studied in species which would be considered 'optimal' candidates for possessing this type of memory. This includes species which cache large number of items in many different locations (Scheid \& Bugnyar 2008) and species which are highly social and likely to suffer from high levels of cache theft as a result (Scheid \& Bugnyar 2008; Bednekoff \& Balda 1996b; a). While New Zealand robins do not fall into either of these categories they do have a number of unique traits which make them an interesting study species for this type of experiment.

Robin's naivety and lack of pronounced anti-predator behaviours make them an excellent species in which to investigate the boundaries of a variety of cognitive traits. As a result of their unique ecological history robins are easily enticed into participating in experiments requiring decision making and active participation on the part of the bird. Numerosity experiments involving a human demonstrator hiding mealworms (Hunt et al. 2008) showed that robins are capable of accurately locating food items that they have watched an individual of another species hide. This attentiveness to the actions of others suggested that New Zealand robins may be able to display observational spatial memory under experimental conditions. Demonstration of OSM in a species which may not be considered an 'optimal' candidate would expand our knowledge of the conditions required for the evolution and development of these cognitive systems. Additionally Hunt 
et al.'s (2008) work demonstrated that robins maintain complex internal recollections of the number of items they have watched being cached.

While most corvid species appear to perform at above chance levels on OSM studies, other avian food-hoarding species such as chickadees have failed to show improved accuracy for locating caches they have observed being made by others (Baker et al. 1988). This suggests that OSM is a specialised memory system and that there may be cognitive or evolutionary constraints on its development. Some work has been done looking at what factors influence species-level differences in OSM, such as the effect of sociality or caching specialization on cache retrieval accuracy (Bednekoff \& Balda 1996a; Scheid \& Bugnyar 2008). However there is currently minimal literature on the influence of small scale factors on intraspecific OSM ability. Additionally this study included the use of variable rewards which added a further layer of complexity to the problem. The birds were required to not only remember and recall the location where they observed food being hidden but had to make a numerical judgment regarding the relative values of two rewards.

Being highly territorial, New Zealand robins would be expected to have well developed spatial memory in order to accurately define and defend their territory boundaries. As robins are a food hoarding species, spatial memory is also likely to play a significant role in their ability to locate and retrieve their own caches. While robins make no attempt to cover or disguise their caches in any way, cache sites are usually located higher in the canopy than their preferred foraging height (Powlesland 1980). This reduces the likelihood of either the caching bird or its mate accidentally recovering the cache during normal foraging activities, although opportunistic cache theft by other species has been documented (Steer \& van Horik 2006). These features suggest that robins possess good spatial memory; however this does not necessarily translate directly to good observational spatial memory. Previous work by Hunt et al. (2008) showed that robins were capable of locating prey that they had observed a human experimenter hiding. While his did not 
involve a memory component, it suggested that this species may utilize OSM in natural pilfering situations.

North Island robins do not live in highly social groups which would suggest that they are unlikely to lose a high proportion of their caches to pilfering by conspecifics. Male robins are typically dominant over food resources (Alexander et al. 2005) and will often aggressively displace females (Burns \& Steer 2006). This results in an increased level of prey acquisition by males, and consequently higher levels of caching compared to females (Burns 2009; Burns \& van Horik 2007). Because robin pairs are typically unrelated there is no direct kin benefit in tolerating high levels of cache theft by an individual's mate. Despite this pilferage rates are high among both sexes. Female-made caches are as likely to be recovered by the male of a pair as they are by the female who created the cache. Conversely male-made caches are nearly twice as likely to be recovered by the female as to be recovered by the male (Burns \& van Horik 2007). This sexual conflict for resources results in high levels of reciprocal cache theft and provides ideal conditions in which observational spatial memory may develop. This is especially likely to be true for female robins, as there is a high risk of aggression if a male returns while the female is pilfering or recaching his cached food items. Reliance on pilfering for a significant proportion of their food would increase the selective pressure for females to develop strategies which allow them to pilfer more effectively and hence compete more equally for resources with their mates. Unfortunately the subordinate nature of females makes it more difficult to conduct experiments in the field as the females are usually displaced by their mate.

A criticism of many animal cognition studies is that they often utilize trained individuals in highly artificial lab environments (Steer 2006; Bednekoff \& Balda 1996b). This has led to the suggestion some animal memory studies are not representative of natural or innate abilities. For this reason New Zealand robins provide ideal models for conducting comparative cognition studies. Their unique ecology allows experiments to be conducted on wild, relatively untrained individuals, providing important insights into the cognitive 
mechanisms which underpin behaviour. Observational spatial memory is an advanced memory trait, however our current understanding in this area suggests that robins are likely to be capable of utilizing sophisticated cognitive tools in order to track both their own and others food caches. 


\section{Methods}

\section{Study Site}

All experiments were conducted at Zealandia (formerly Karori Wildlife Sanctuary; Fig. 2), a 225 hectare fragment of regenerating native bush located close to central Wellington, New Zealand $\left(41^{\circ} 18^{\prime} \mathrm{S}, 174^{\circ} 44^{\prime} \mathrm{E}\right)$. The sanctuary is surrounded by a predator-proof fence designed to exclude introduced mammalian species. Intensive pestcontrol programs have successfully removed all exotic mammal species with the exception of mice. This has allowed the translocation and establishment of species which are otherwise extinct or existing in only remnant populations on mainland New Zealand, including North Island robins. As a result Zealandia's avifauna is a mixture of between 40 and 50 native and exotic species (Steer 2006).

The structure of the forest in Zealandia is similar to the preferred habitat of New Zealand robins (Borkin et al. 2008; Steffens et al. 2005; Duncan et al. 1999) and consists of a mixture of native and exotic species, although upper canopy and emergent species are predominantly exotic conifers (Pinus radiata and Cupressus macrocarpa). Understory plants are generally regenerating native species. A population of 76 North Island robins were first translocated into the sanctuary in 2001 from nearby Kapiti Island (Miskelly et al. 2005). Since then the population has bred successfully and is no longer being intensively monitored or banded. The last census of the robin population in 2008 estimated the total sanctuary population at approximately 600 birds, including around 150 colour banded individuals (McGavin 2009). 


\section{Zealandia, Wellington}

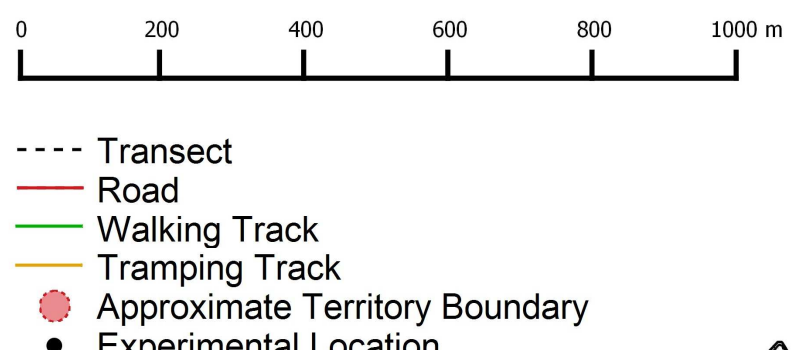

- Experimental Location

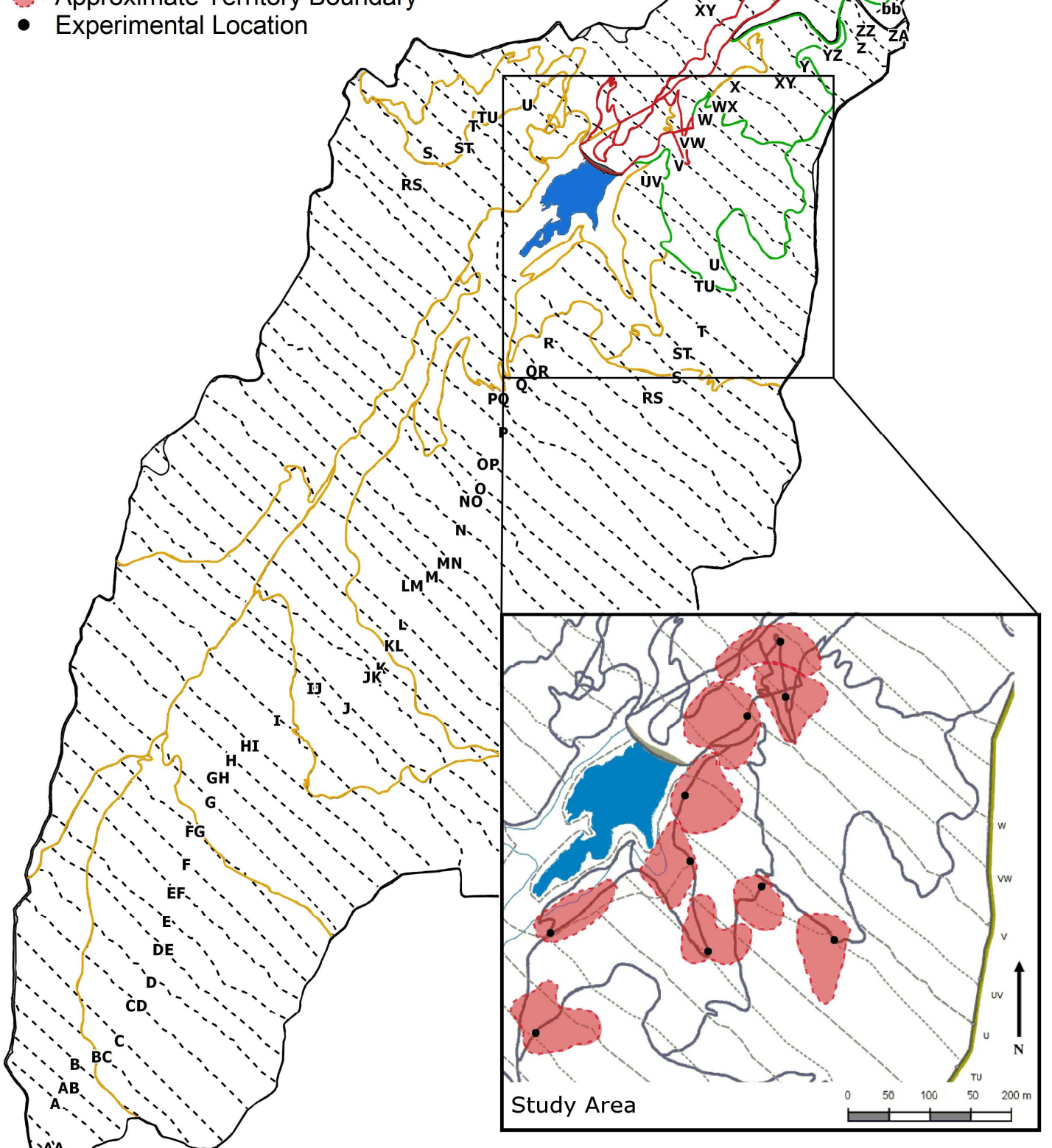

Figure 2: Map of Zealandia showing major tracks and transects. Enlargement shows the locations and approximate territories of the ten birds used in this study. 


\section{Experimental Design}

Ten individual North Island robins were used for this study and all had previously participated in food hoarding and/ or numerosity experiments (Hunt et al. 2008; Garland, pers. com; Steer 2006). All birds were adult males of $18+$ months of age at the start of the trials (Zealandia banding data). There is potential for bias if juvenile birds have less developed observational spatial memory through inexperience in caching and pilfering so sub adult birds were excluded from trials. Birds were all banded with unique band combinations consisting of three colour bands and a metal band, allowing for accurate repeat identification.

The experimental arena in which trials were conducted was similar in design to those used in previous robin numerosity experiments (Hunt et al. 2008). Each arena consisted of a tree branch containing 2, 3 or 4 artificial cache sites. The total lengths of branches measured 300, 450, and $600 \mathrm{~mm}$ respectively. Artificial cache sites consisted of wells, 3 $\mathrm{cm}$ long and $2 \mathrm{~cm}$ deep set into the branches. Each well could be covered by a leather flap attached at one side by a screw swivel, allowing the contents to be obscured from view (Fig. 3). This set-up allowed mealworms (Tenebrio molitor larvae) to be placed inside the cache sites and the birds were able to demonstrate decision making regarding which cache to open. New Zealand robins often manipulate large leaves while foraging on the forest floor. As a result all the birds used in this study were able to open the artificial caches with little or no prior training.

The study was conducted as a two-factor, fully crossed experiment, consisting of two independent variables, 'number of cache sites' and 'retention interval'. The first independent variable consisted of the number of artificial cache sites comprising the experimental arena. The experimental branches presented contained either 2, 3, or 4 artificial cache sites. This was to test whether accuracy in cache recovery declines as a function of the number of sites being discriminated between. Robins typically utilise less than three cache sites, even when presented with a super-abundant supply of prey (van 
Horik \& Burns 2007). As a result the number of artificial cache sites in this study was chosen to cover this range as this was considered to be an ecologically-relevant number.

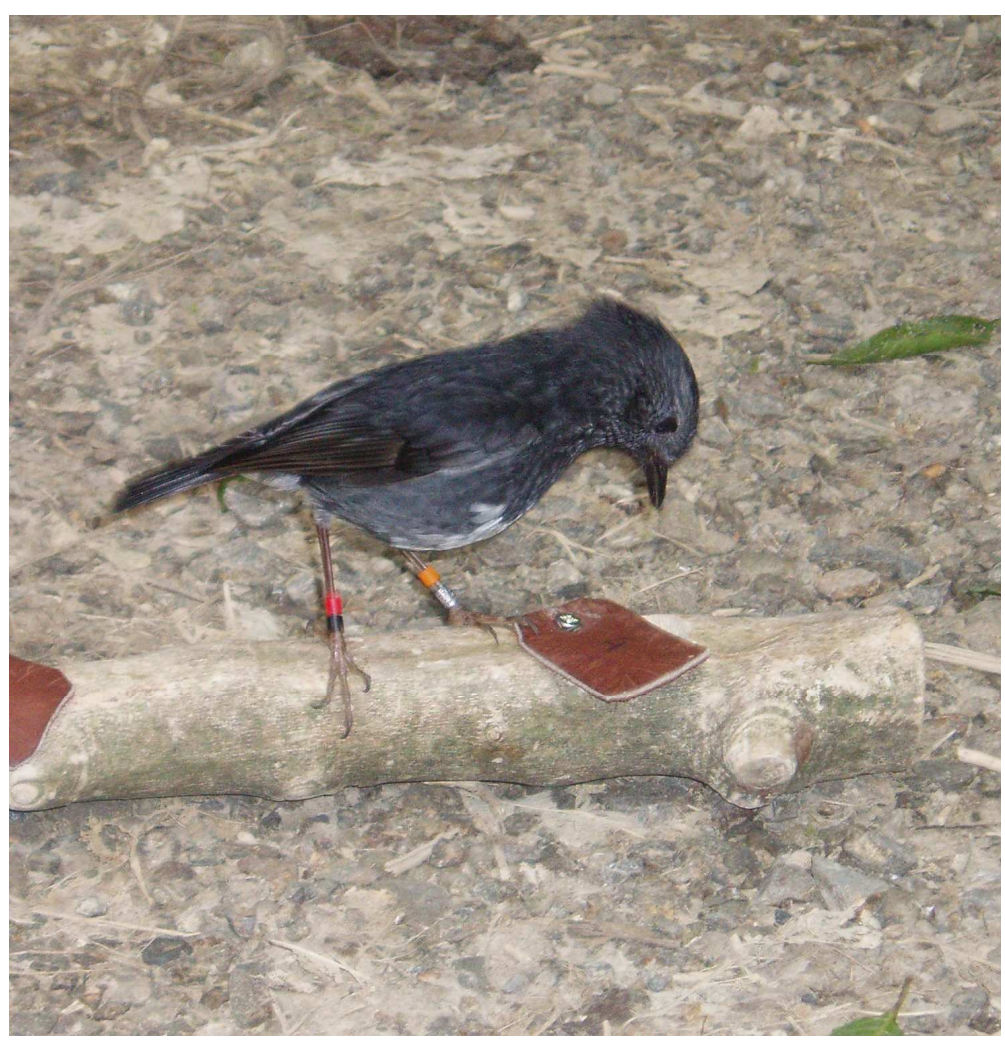

Figure 3: A North Island robin investigating the contents of an artificial cache site during an experimental trial.

The second independent variable was retention interval. Retention interval was defined as the period of time between the bird observing the last mealworm being placed in the cache site and obscured from view, and the bird being allowed access to retrieve the mealworms. The shortest retention interval in this study was 0 seconds, i.e. the bird was allowed immediate access to the cache sites once the leather flaps had been closed. To test for memory two longer retention intervals of 10 and 60 seconds were used. New Zealand robins have been shown to maintain caches for only short periods (Powlesland 1980). Robin also have generally short intervals of less than 30 minutes between caching and pilfering (van Horik \& Burns 2007). As a result the retention intervals used in this 
study were generally shorter than those used in the majority of corvid trials because these are more ecologically relevant for New Zealand robins.

Time limits were also constrained by the difficulties of working with wild individuals. Robins have short attention spans, as the necessity of foraging means that time spent observing a person is only profitable if the energy reward is greater than that which could be obtained in the same amount time spent foraging. Without the immediate stimulus of seeing the mealworms the birds quickly lose interest. If trials had been conducted over longer timeframes a bird is likely to abandon the experiment altogether as the imperative to forage and patrol their territory would override any other incentive to stay. Precise, long-term retention intervals are possible when using captive aviary populations, however the logistics of doing this in the field are significantly more difficult. It was not realistic to leave the apparatus in the field due to public access along the pathways which may have resulted in tampering and invalid results.

The two-way crossed model was repeated across three experiments which differed in the number of mealworms offered. This was to test the hypothesis that observational memory is negatively affected by increasing numbers of prey. Large numbers of prey items (of more than four) were not used as previous work has shown that robins are capable of accurate number discriminations up to at least 12 items (Hunt et al. 2008). Numbers of less than four are able to be discriminated between innately by most species (Trick \& Pylyshyn 1994). In Experiment 1 the robins observed 1 mealworm being placed in of the artificial cache sites. In Experiments 2 and 3 the birds observed 2 or 3 mealworms respectively being hidden in one of the cache sites. Additionally, a variable reward system was used in Experiments 2 and 3. In these experiments an additional 1 mealworm was placed in another cache site, see Table 1 for a summary of experimental factors. This tested the ability of the birds to discriminate between two varying values of reward within the observational spatial memory paradigm. 
Table 1: Summary of experimental design

\begin{tabular}{|lccc|}
\hline & \multicolumn{3}{c|}{ Factors } \\
\cline { 2 - 4 } & Retention Intervals & Cache Sites & Mealworms \\
\hline Experiment 1 & $0,10,60$ & $2,3,4$ & 1 \\
\hline Experiment 2 & $0,10,60$ & $2,3,4$ & $1 \vee 2$ \\
\hline Experiment 3 & $0,10,60$ & $2,3,4$ & $1 \vee 3$ \\
\hline
\end{tabular}

All treatment combinations across the three experiments were repeated four times with each of the 10 study birds a total of 1080 separate experimental trials. To control for learning effects the order in which the treatment combinations were conducted was randomly assigned in advance for each bird.

\section{Experimental Protocol}

Trials were conducted between July and December 2010. The birds used in the experiment were located by spot-mapping along a series of tracks traversing the valley. Once the approximate boundaries of the bird's territory had been established the trials were always conducted at the same site (Fig. 2). This allowed trials to be conducted away from immediate territory borders where the birds were more likely to be distracted by the possible presence of neighbouring males. Utilizing the same locations also reduced other possible site biases as well as making it easier to locate the same birds on a regular basis.

One of the disadvantages of field studies is the inability to standardise environmental variation and other external factors. Conducting trials in the same location within an individual's territory reduced the environmental noise, although it was impossible to completely remove it. On subsequent occasions the birds were often waiting at the beginning of the trials. In instances where this was not the case the birds were able to be 
attracted through loud hand clapping. Loud noises suggest possible environmental disturbance which robins often exploit in order to capture prey which is flushed from the leaf-litter.

The three experiments were conducted using the same methodology. Once the bird was located the experimental apparatus was placed on the track and trials began once the bird had approached within 2 metres of the experimenter. In instances where the bird was reluctant to approach they were easily lured using small pieces of stick thrown onto the track. Trials were only conducted once the birds were oriented towards the experimenter and appeared to be watching, in order to reduce possible effects of attentiveness on the performance in the task. The artificial cache sites were initially presented with the leather flaps open so the bird was able to see they were empty. Mealworms were then held up individually and displayed to the bird before being placed sequentially into the cache site (at a rate of approximately 5 seconds per item) and the leather flaps closed. All mealworms used in the study were a standard size of approximately $2 \mathrm{~cm}$ in length. The cache site into which the mealworms were placed was randomly assigned in advance to counter possible site bias or orientation preferences. For Experiments 2 and 3 where there was a variable reward, the order in which the sets of mealworms (i.e. larger number vs. smaller number) were placed in the cache sites was also randomised to counter any potential order preferences.

In trials with a 0 second retention interval the experimenter then immediately stepped back two meters and the robin was allowed to select and open one cache site. A cache was considered 'selected' if the bird actively removed the leather flap from a well. After the bird had opened one well and retrieved the contents (if a correct choice was made) the apparatus was removed to prevent the birds from continuing to open caches. The birds were non-differentially reinforced and allowed to retrieve any mealworms in the cache they had chosen. If the bird was allowed to continue opening all cache sites there would be a reduced incentive to make a "correct" choice with the first cache. The apparatus had to be removed or the robins would quickly learn that it can receive the reward (i.e. the 
hidden mealworms) by simply opening all the cache sites until the mealworms were located. This could be achieved without being required to actively observe and recall which cache site contained the mealworms.

The same procedure was used in trials with retention intervals of 10 and 60 seconds, however after the leather flaps were closed the whole apparatus was covered with an opaque sheet. This created a visual barrier which obscured the cache sites in order to visually remove them from the bird's field of view. By effectively removing the cache sites from view the bird was required to actively remember which cache contained the mealworms in order to make a correct decision when allowed access. After the appropriate retention interval (10 or 60 seconds) the sheet was removed and the experimenter stepped back and the trial proceeded as above.

Each individual bird completed a maximum of two trials per day. When two trials were conducted on the same day they were always separated by a minimum of two hours. This reduced the likelihood of site bias through recalling cache sites where prey was previously acquired. Occasionally trials were halted due to heavy rain or strong wind during which the robins were less willing to participate. Due to the nature of the field studies none of the birds were food-deprived prior to the experimental trials; however robins forage throughout the day (van Horik \& Burns 2007) and are always eager to participate in trials and acquire prey when offered by an experimenter (Powlesland 1980; 1981b; a).

\section{Data Analysis}

\section{Non-Random Decision Making}

All statistical analysis was done using PASW (Predictive Analytics SoftWare v. 18.0.0). A 'successful' choice was defined as a trial in which the bird selected and removed the leather flap from the cache site containing the largest number of mealworms on the first 
attempt. 'Individual' was used as the unit of replication. A mean success rate was calculated as a percentage of successful choices for each treatment condition across the four replicates per individual bird. This gave ten data points for each of the 9 treatment combinations over three experiments. Each data point consisted of a percentage success rate between 0 and 100 for each of the ten individual birds.

If the birds were selecting cache sites at random then the chance a particular caches site would be selected will vary as a function of the total number of sites presented. When there are two sites the likelihood of a 'success' by chance is $50 \%$, compared to $33 \%$ when

there are three sites presented and 25\% when there are four sites. If robins display OSM then they should be expected to perform above the level of chance.

To test for non-random, above chance, decision making the predicted chance success rate for each trial was subtracted from the observed success rate. This created a standardised data set by removed the bias of lower numbers of cache sites producing elevated success rates. For each of the three experiments the variables 'number of cache sites' and 'retention interval' were also compared to chance. Across the three experiments there were 9 possible treatment combinations of variables, each consisting of one level of number of cache sites $(2,3$, or 4$)$ and retention interval $(0,10$, or 60 seconds). These treatment combinations were also compared to chance using single sample t-tests.

The data for the birds selecting the smaller of the two presented mealworm rewards (Experiments 2 and 3) was also standardised by subtracting the chance level from the observed result. This was compared to difference from zero using two single sample ttests.

\section{Effects of Independent Variables}

After establishing whether the birds were able to locate experimentally hidden prey more often than expected by chance, an ANOVA was conducted for each experiment to test whether observational spatial memory varies with the number of cache sites or retention 
interval, as well as any interactions between these two variables. Separate analyses were conducted for each of the three experiments containing differing numbers of prey items. As above, the data set was standardised by using the observed success rate for each treatment minus the success rate expected by chance. This was analysed using three ANOVAs with the dependent factors consisting of the success rate for each of the three experiments. Independent factors were the number of cache sites and the retention intervals in a fully crossed two-factor model. Individual bird was included as a random factor to account for any possible variation in ability between the ten individual study subjects. Additional ANOVAs were also conducted omitting 'Individual' as a random factor to increase the power of the test.

\section{Additional Factors}

As trials were conducted over several months this was analysed separately using a linear regression model to detect any trends in success rate across the study period. On some days the robins each participated in two trials, one in the morning and one later in the day, after a period of at least two hours. This was analysed using an independent samples t-test to determine if time of day had an effect on the bird's accuracy. A chi-squared test was used to establish non-random orientation and site preferences for any of the artificial cache sites.

Results are represented graphically using PASW Statistics. Bar charts were used to represent average success rates for the three experiments and combinations of independent variables in order to visually assess the direction of trends. The nine combinations of variables across the three experiments were also represented graphically in two bar charts. The average success rate for each individual bird across all trials was graphed using a bar chart and the average success rate on each day across the sample period was represented using a scatter plot including a regression line showing the direction of any linear trends. 


\section{Results}

\section{Non-random Decision Making for Larger Numbers of Prey}

The three experiments were tested for non-random decision making with regards to selecting the larger presented number of mealworms. Each level of the two independent variables (number of cache sites and retention interval) was tested against chance expectation (Fig. 4) for each of the three experiments. All different levels of number of cache sites $(2,3$, or 4 sites) were significantly above chance across all three experiments $(P=<0.021)$ (Fig. 4a, Table 2-4). All retention intervals (0, 10, and 60 seconds) were also significantly above chance across the three experiments $(P<0.017$ for all trials $)$ (Fig. 4b, Table 2-4). This strongly suggests that North Island robins are capable of displaying observational spatial memory across at least short time intervals.

Each of the three experiments consisted of two independent variables (number of cache sites and retention interval), each with three levels (2, 3 or 4 sites; 0,10 or 60 seconds) giving a total of 9 possible treatment combinations across the three experiments (Fig. 5). These were also analysed individually using single sample t-tests. Some combinations of treatments did not differ significantly from chance as indicated by Fig. 6. See Table 5 for full statistics. 

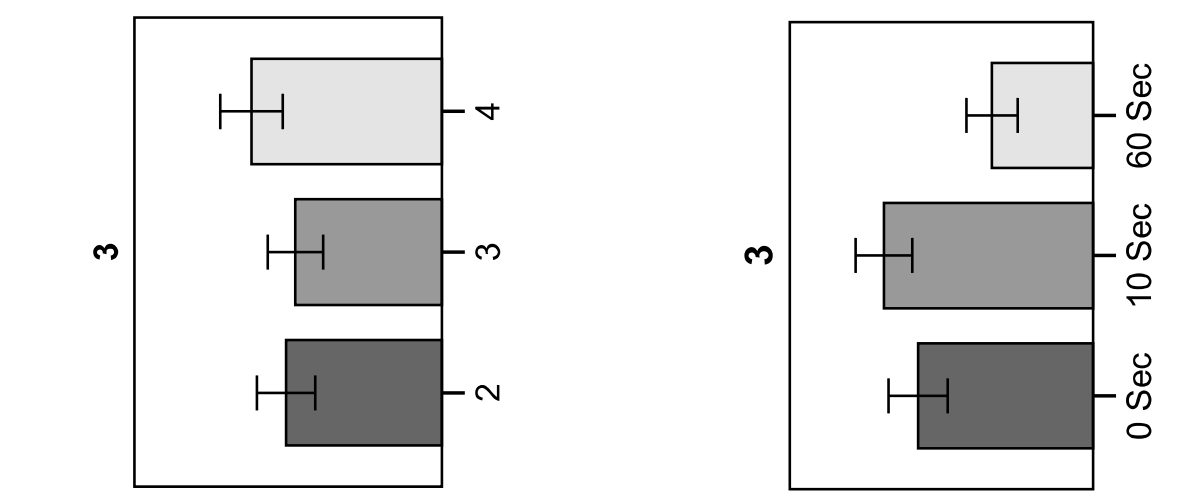

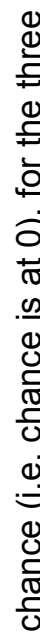
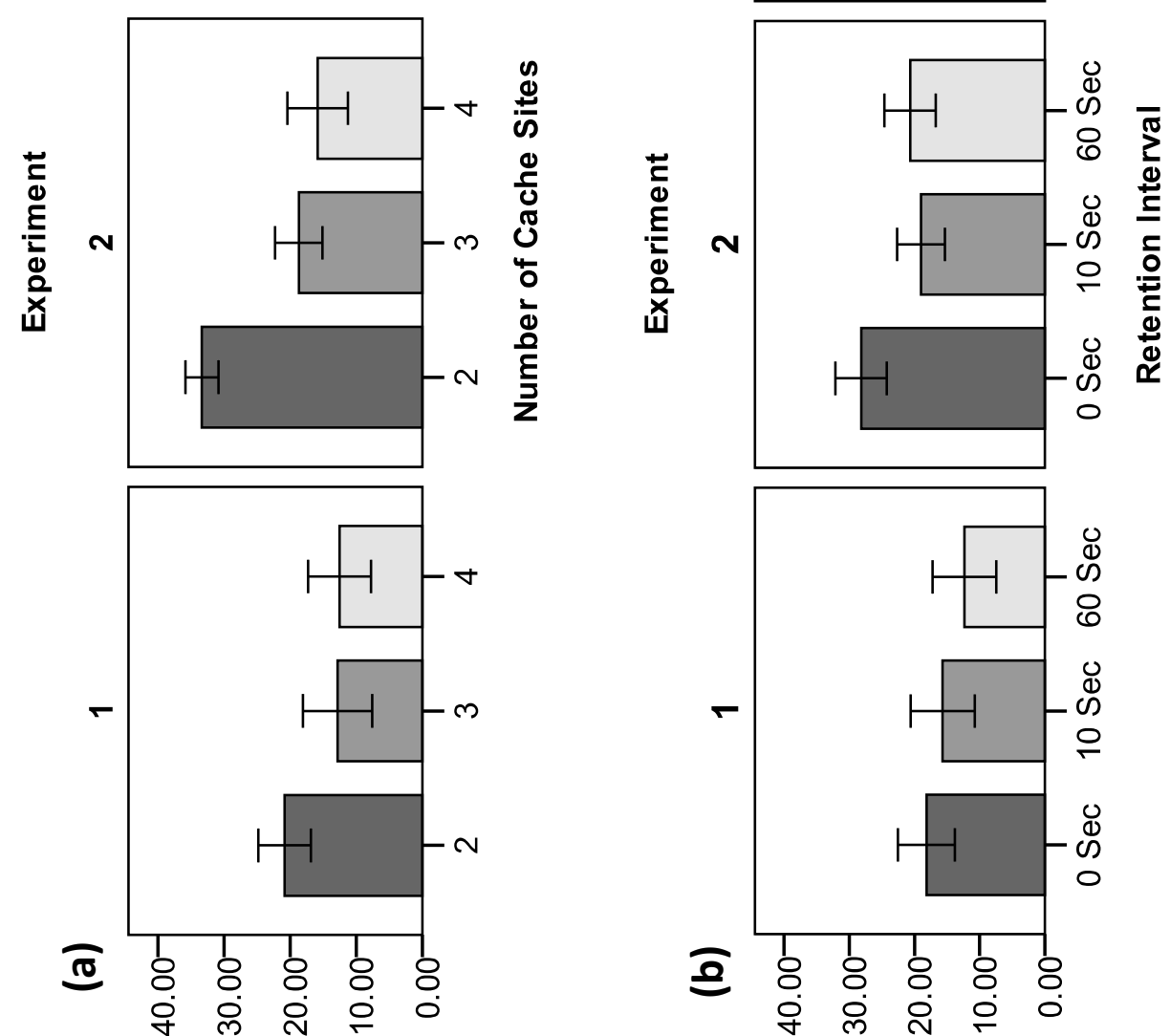

(\%) әэuеपว

snu!w әəеy

(\%) әэuеपว

snu!w әреy

ssooons ueow

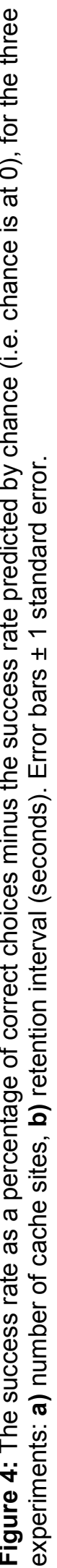


Table 2: Summary of single sample T-tests for above zero success rates for Experiment 1 where the birds were presented with a reward of 1 mealworm. Shows each of the three levels of the variables 'number of cache sites' and 'retention interval'.

\begin{tabular}{|lllll|}
\hline \multicolumn{1}{|c}{ Variable } & Mean & $\begin{array}{c}\text { Standard } \\
\text { Error }\end{array}$ & T & Sig. \\
\hline 2 cache sites & 20.83 & 21.86 & 5.22 & 0.000 \\
\hline 3 cache sites & 12.83 & 26.68 & 2.45 & 0.021 \\
\hline 4 cache sites & 12.50 & 26.06 & 2.63 & 0.014 \\
\hline $0 \mathrm{Sec}$ & 18.17 & 23.90 & 4.16 & 0.000 \\
\hline $10 \mathrm{Sec}$ & 15.67 & 26.83 & 3.20 & 0.003 \\
\hline $60 \mathrm{Sec}$ & 12.33 & 26.77 & 2.52 & 0.017 \\
\hline
\end{tabular}

Table 3: Summary of single sample T-tests for above zero success rates for Experiment 2. The birds were presented with a high-value reward of 2 mealworms and a low-value reward of 1 mealworm. Shows each of the three levels of the variables 'number of cache sites' and 'retention interval'.

\begin{tabular}{|lcccc|}
\hline \multicolumn{1}{|c}{ Variable } & Mean & $\begin{array}{c}\text { Standard } \\
\text { Error }\end{array}$ & $\mathbf{T}$ & Sig. \\
\hline 2 cache sites & 33.33 & 13.67 & 13.36 & 0.000 \\
\hline 3 cache sites & 18.67 & 19.62 & 5.21 & 0.000 \\
\hline 4 cache sites & 15.83 & 24.99 & 3.47 & 0.002 \\
\hline $0 \mathrm{Sec}$ & 28.17 & 21.59 & 7.15 & 0.000 \\
\hline $10 \mathrm{Sec}$ & 19.00 & 20.01 & 5.20 & 0.000 \\
\hline $60 \mathrm{Sec}$ & 20.67 & 21.52 & 5.26 & 0.002 \\
\hline
\end{tabular}

Table 4: Summary of single sample T-tests for above zero success rates for Experiment 3. The birds were presented with a high-value reward of 3 mealworms and a low-value reward of 1 mealworm. Shows each of the three levels of the variables 'number of cache sites' and 'retention interval'.

\begin{tabular}{|lcccc|}
\hline \multicolumn{1}{|c}{ Variable } & Mean & $\begin{array}{c}\text { Standard } \\
\text { Error }\end{array}$ & $\mathbf{T}$ & Sig. \\
\hline 2 cache sites & 22.50 & 23.07 & 5.34 & 0.000 \\
\hline 3 cache sites & 21.17 & 21.86 & 5.30 & 0.000 \\
\hline 4 cache sites & 27.50 & 24.87 & 6.06 & 0.000 \\
\hline $0 \mathrm{Sec}$ & 25.67 & 23.84 & 5.90 & 0.000 \\
\hline $10 \mathrm{Sec}$ & 30.67 & 22.88 & 7.35 & 0.000 \\
\hline $60 \mathrm{Sec}$ & 14.83 & 20.61 & 3.94 & 0.000 \\
\hline
\end{tabular}




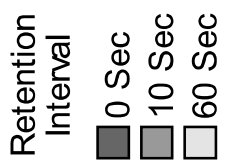

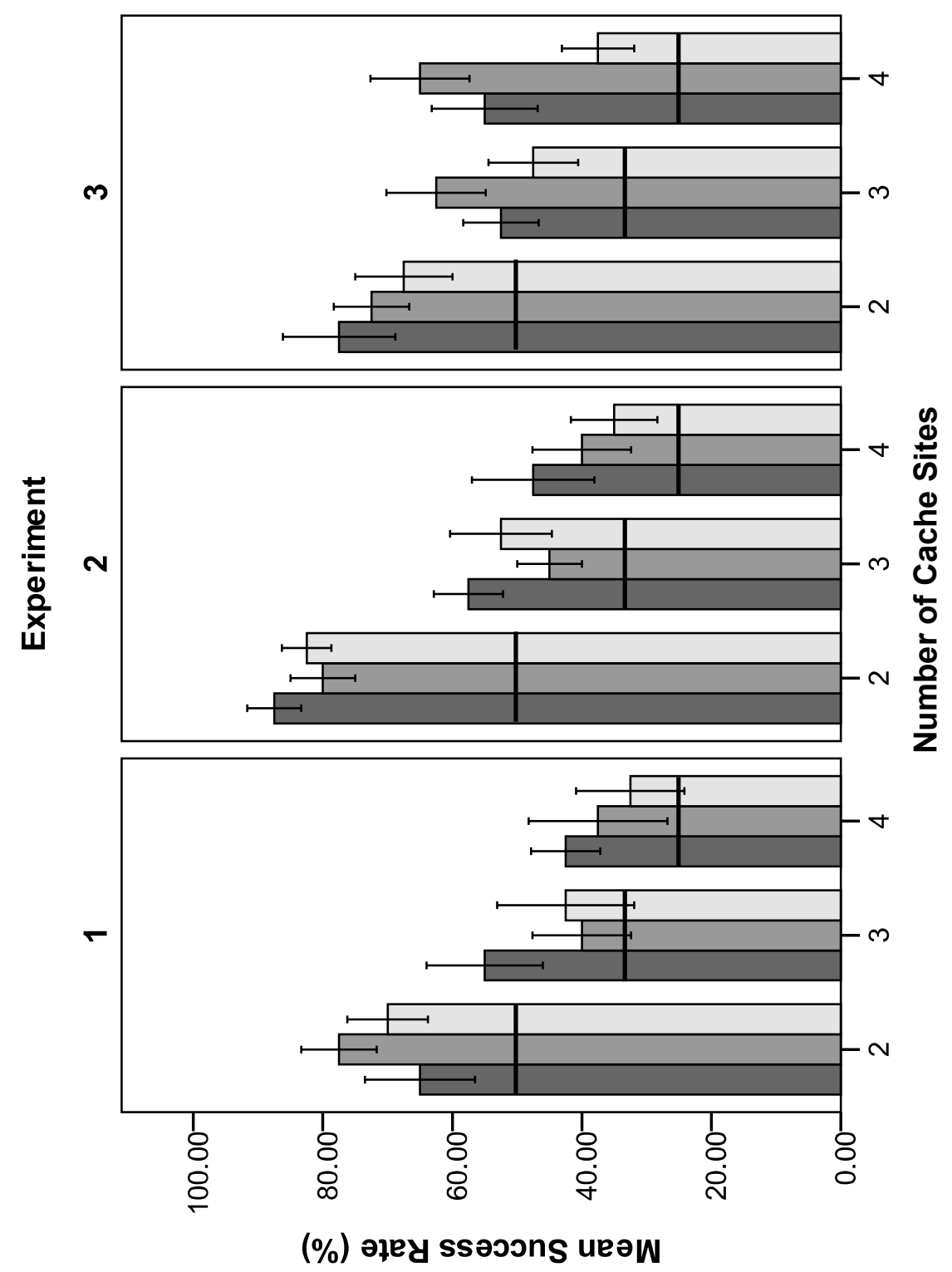

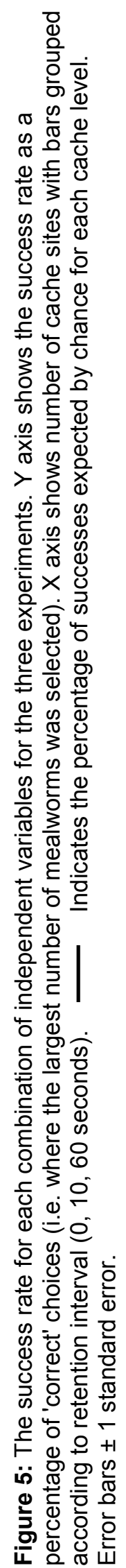




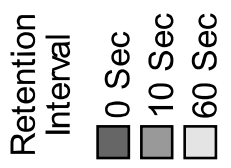

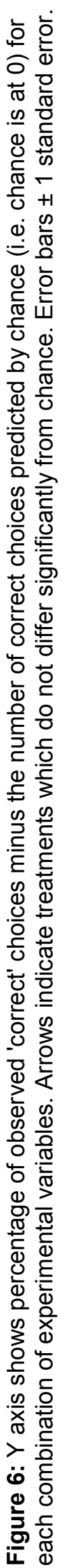

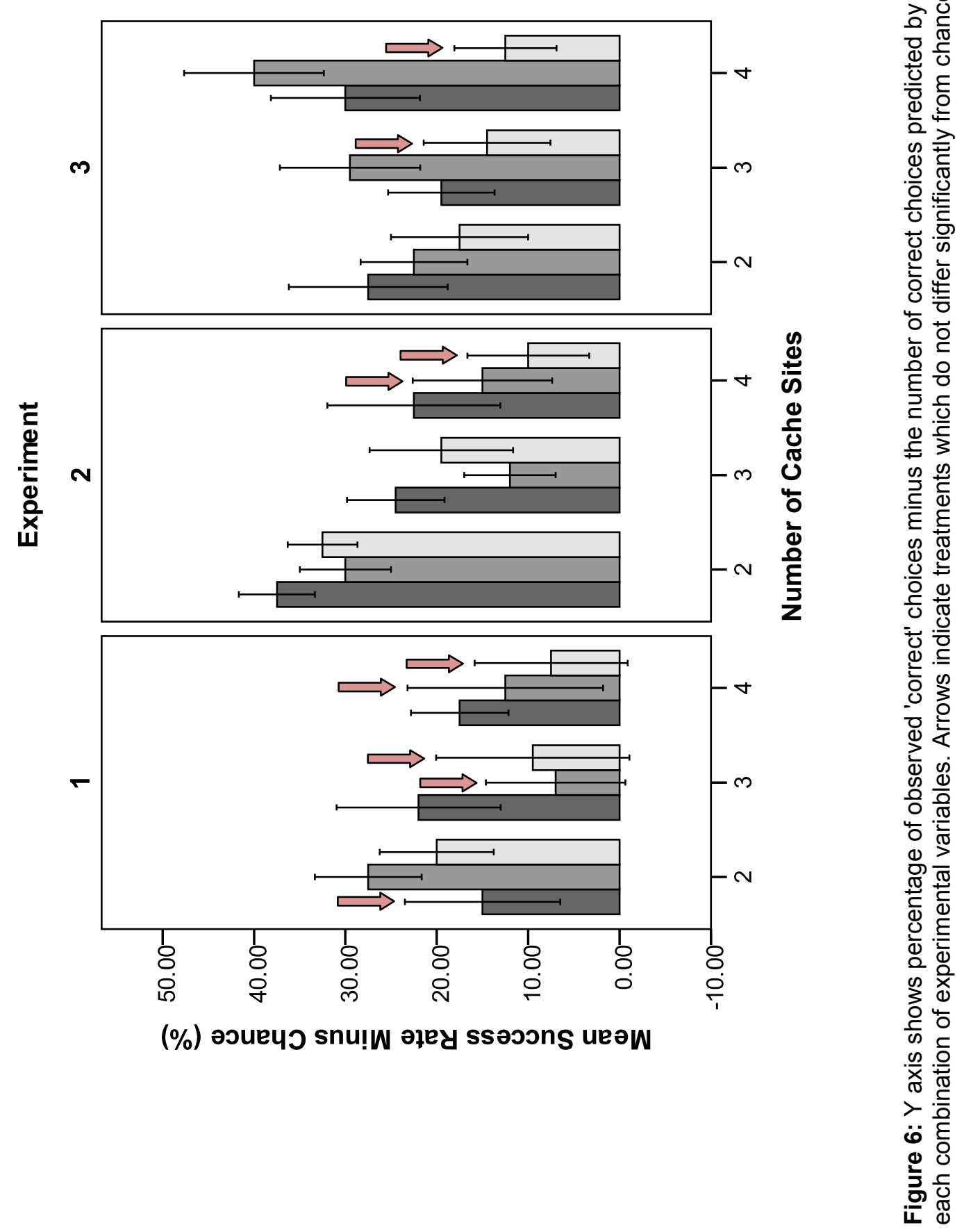


Table 5: Single sample T-test analysis for above-chance success rate of all nine possible combinations of the variables 'number of cache sites' and 'retention interval' across Experiments $1-3$, which differed in the maximum number of mealworms offered as a reward.

\begin{tabular}{|c|c|c|c|c|c|c|}
\hline Treatment & Experiment & $\begin{array}{c}\text { Number of } \\
\text { Cache } \\
\text { Sites }\end{array}$ & Time & Mean & $\mathbf{T}$ & Sig. \\
\hline 1 & 1 & 2 & 0 & 65.00 & 1.765 & .111 \\
\hline 2 & 1 & 2 & 10 & 77.50 & 4.714 & .001 \\
\hline 3 & 1 & 2 & 60 & 70.00 & 3.207 & .011 \\
\hline 4 & 1 & 3 & 0 & 55.00 & 2.451 & .037 \\
\hline 5 & 1 & 3 & 10 & 40.00 & .917 & .383 \\
\hline 6 & 1 & 3 & 60 & 42.50 & .898 & .392 \\
\hline 7 & 1 & 4 & 0 & 42.50 & 3.280 & .010 \\
\hline 8 & 1 & 4 & 10 & 37.50 & 1.168 & .273 \\
\hline 9 & 1 & 4 & 60 & 32.50 & .896 & .394 \\
\hline 10 & 2 & 2 & 0 & 87.50 & 9.000 & .000 \\
\hline 11 & 2 & 2 & 10 & 80.00 & 6.000 & .000 \\
\hline 12 & 2 & 2 & 60 & 82.50 & 8.510 & .000 \\
\hline 13 & 2 & 3 & 0 & 57.50 & 4.592 & .001 \\
\hline 14 & 2 & 3 & 10 & 45.00 & 2.400 & .040 \\
\hline 15 & 2 & 3 & 60 & 52.50 & 2.480 & .035 \\
\hline 16 & 2 & 4 & 0 & 47.50 & 2.377 & .041 \\
\hline 17 & 2 & 4 & 10 & 40.00 & 1.964 & .081 \\
\hline 18 & 2 & 4 & 60 & 35.00 & 1.500 & .168 \\
\hline 19 & 3 & 2 & 0 & 77.50 & 3.161 & .012 \\
\hline 20 & 3 & 2 & 10 & 72.50 & 3.857 & .004 \\
\hline 21 & 3 & 2 & 60 & 67.50 & 2.333 & .045 \\
\hline 22 & 3 & 3 & 0 & 52.50 & 3.343 & .009 \\
\hline 23 & 3 & 3 & 10 & 62.50 & 3.840 & .004 \\
\hline 24 & 3 & 3 & 60 & 47.50 & 2.095 & .066 \\
\hline 25 & 3 & 4 & 0 & 55.00 & 3.674 & .005 \\
\hline 26 & 3 & 4 & 10 & 65.00 & 5.237 & .001 \\
\hline 27 & 3 & 4 & 60 & 37.50 & 2.236 & .052 \\
\hline
\end{tabular}




\section{Numerical Discrimination between Variable Rewards}

Additional T-tests were used for Experiments 2 and 3 to assess whether the robins selected the lower of the variable reward (i.e. the cache site containing only 1 mealworm) at a level which differed from chance. In both experiments the cache site with only 1 mealworm was selected at significantly below chance level $(P<0.005)$ (Experiment $1, T$ $=-5.84$; Experiment 2, $T=-6.87$ ).

\section{Analysis of Independent Variables}

Results were consistent with the hypothesis that both the number of cache sites and retention interval affect the ability of robins to correctly locate hidden mealworms.

Levene's Test was nonsignificant for all four analyses $(P>0.075)$. $(P>0.313)$.

\section{Experiment 1}

Neither number of cache sites nor retention interval were significant predictors of success rate in this experiment. Both the interaction between number of cache sites and retention interval and the random factor 'individual' were also non-significant (Table 5).

Table 6: ANOVA table for Experiment 1 with independent variables 'Number of cache sites' and 'Retention interval', including Individual bird as a random factor.

\begin{tabular}{|lccccc|}
\hline & $\begin{array}{c}\text { Sum of } \\
\text { Squares }\end{array}$ & df & Mean Square & F & Sig. \\
\hline Intercept & 21313.611 & 1 & 21313.611 & 62.073 & .000 \\
\hline Individual & 3090.278 & 9 & 343.364 & .405 & .903 \\
\hline Number of Cache Sites & 1335.556 & 2 & 667.778 & .865 & .438 \\
\hline Retention Interval & 513.889 & 2 & 256.944 & .342 & .715 \\
\hline Cache ${ }^{*} \mathrm{RI}$ & 2069.444 & 4 & 517.361 & .766 & .554 \\
\hline
\end{tabular}




\section{Experiment 2}

Number of cache sites was significant in determining the likelihood of a successful choice for this experiment. Fig. 4a indicates that trials involving 2 cache sites had a higher likelihood of success compared to 3 or 4 cache sites. Retention interval, individual and the interaction between number of cache sites and retention interval were all nonsignificant for this experiment (Table 7).

Table 7: ANOVA table for Experiment 2 with independent variables 'Number of cache sites' and 'Retention interval', including Individual bird as a random factor.

\begin{tabular}{|lccccc|}
\hline & $\begin{array}{c}\text { Sum of } \\
\text { Squares }\end{array}$ & df & Mean Square & F & Sig. \\
\hline Intercept & 46013.611 & 1 & 46013.611 & 89.138 & .000 \\
\hline Individual & 4645.833 & 9 & 516.204 & 1.570 & .313 \\
\hline Number of Cache Sites & 5293.889 & 2 & 2646.944 & 7.573 & .004 \\
\hline Retention Interval & 1430.556 & 2 & 715.278 & 1.828 & .189 \\
\hline Cache ${ }^{*} \mathrm{RI}$ & 444.444 & 4 & 111.111 & .270 & .896 \\
\hline
\end{tabular}

\section{Experiment 3}

Number of cache sites was not a significant predictor of success in this experiment, however retention interval was significant. Fig. $4 \mathrm{~b}$ indicates that in trials with a 60 second retention interval result in a lower rate of success than trials with a retention interval of either 0 or 10 seconds. Neither Individual nor the interaction term were significant (Table 8).

Table 8: ANOVA table for Experiment 3 with independent variables 'Number of cache sites' and 'Retention interval', including Individual bird as a random factor.

\begin{tabular}{|lccccc|}
\hline & $\begin{array}{c}\text { Sum of } \\
\text { Squares }\end{array}$ & df & Mean Square & F & Sig. \\
\hline Intercept & 50646.944 & 1 & 50646.944 & 135.337 & .000 \\
\hline Individual & 3368.056 & 9 & 374.228 & .964 & .567 \\
\hline Number of Cache Sites & 668.889 & 2 & 334.444 & .462 & .637 \\
\hline Retention Interval & 3930.556 & 2 & 1965.278 & 8.035 & .003 \\
\hline Cache ${ }^{*} \mathrm{RI}$ & 1611.111 & 4 & 402.778 & .694 & .601 \\
\hline
\end{tabular}


A separate set of ANOVAs omitting Individual as a random factor was also conducted. This did not affect the outcome of the analysis appreciably, nor did it change the overall significance of any of the results (Table 9).

Table 9: ANOVA summary for the three experiments with independent variables 'Number of cache sites' and 'Retention interval' and excluding Individual as a random factor.

\begin{tabular}{|llccccc|}
\hline & Experiment & Sum of Squares & df & Mean Square & F & Sig. \\
\hline Intercept & 1 & 21313.611 & 1 & 21313.611 & 31.497 & .000 \\
& 2 & 46013.611 & 1 & 46013.611 & 113.588 & .000 \\
& 3 & 50646.944 & 1 & 50646.944 & 98.408 & .000 \\
\hline Number of & 1 & 1335.556 & 2 & 667.778 & .987 & .377 \\
Cache Sites & 2 & 5293.889 & 2 & 2646.944 & 6.534 & .002 \\
& 3 & 668.889 & 2 & 334.444 & .650 & .525 \\
\hline Retention & 1 & 513.889 & 2 & 256.944 & .380 & .685 \\
Interval & 2 & 1430.556 & 2 & 715.278 & 1.766 & .178 \\
& 3 & 3930.556 & 2 & 1965.278 & 3.819 & .026 \\
\hline Cache * RI & 1 & 2069.444 & 4 & 517.361 & .765 & .551 \\
& 2 & 444.444 & 4 & 111.111 & .274 & .894 \\
& 3 & 1611.111 & 4 & 402.778 & .783 & .540 \\
\hline Error & 1 & 54812.500 & 81 & 676.698 & & \\
& 2 & 32812.500 & 81 & 405.093 & & \\
& 3 & 41687.500 & 81 & 514.660 & & \\
\hline
\end{tabular}




\section{Difference between Experiments}

There were differences in success rate between the three experiments, suggesting that the number of mealworms offered as a reward affected the bird's average success rate. In Experiment 1 where the robins were offered only 1 mealworms there was a significantly lower success rate than in the other two experiments where the birds were offered $2(T=$ $-2.03, P=0.46)$ or three $(T=-2.37, P=0.20)$ mealworms. Trials with 2 or 3 mealworms did not differ significantly from each other $(T=-0.32, P=0.75)$.

\section{Differences between Individuals}

There was some variation in average success rates between the ten study birds (Fig. 7) however this was not a significant factor across all experiments when included in the ANOVA model as a random factor (Tables 5-7).

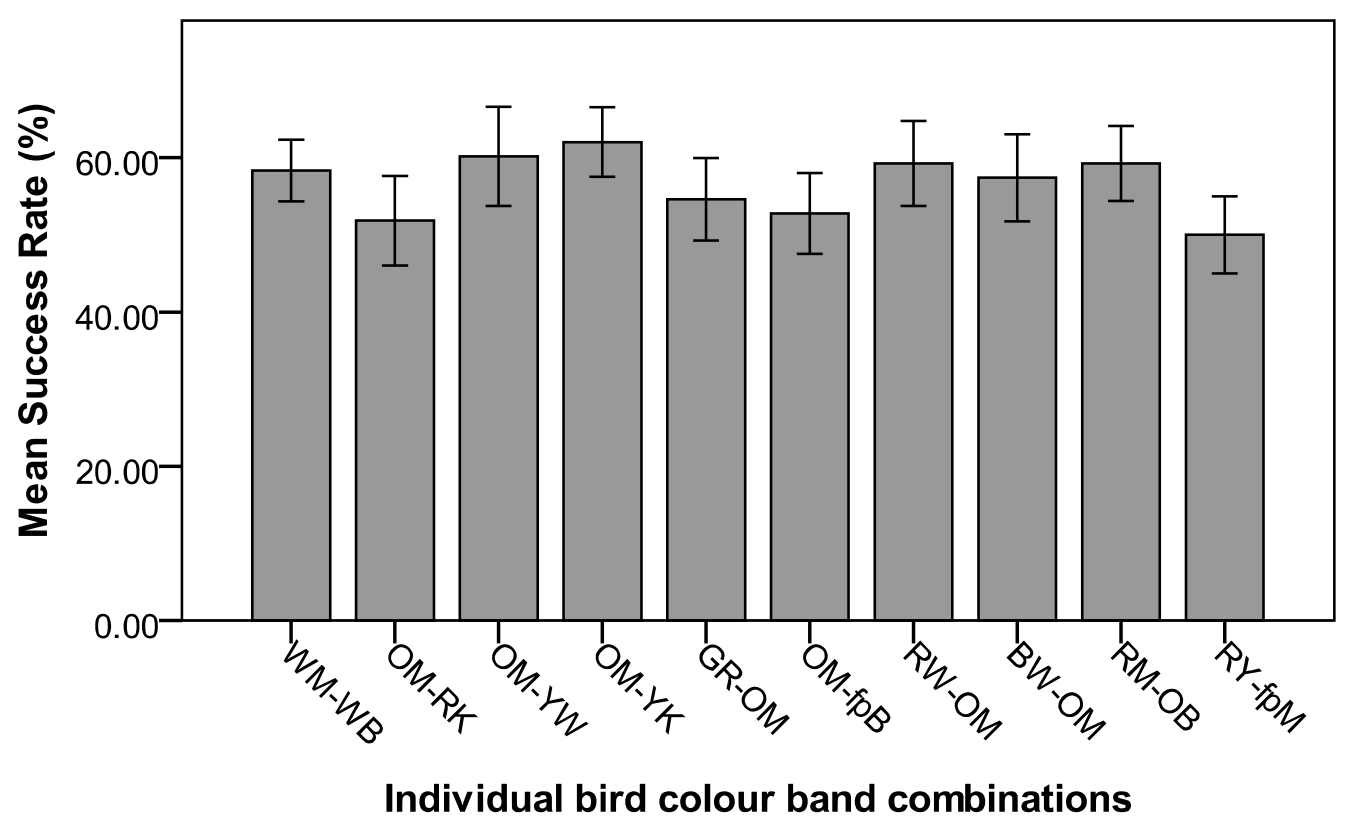

Figure 7: Percentage of successes across all trials by individual bird. Birds are labelled according to their unique coloured leg bands, ordered from oldest to youngest. Error bars \pm 1 se. 


\section{Additional Variables}

\section{Variation over Time}

Because data collection was carried out over a period of months, this covered winter to spring and included the start of the breeding season. A regression analysis of variation between days across the sampling period (Fig. 8) shows an increasing linear trend $(P=$ 0.005). However this trend is not strong $(R=0.086)$ suggesting that there is little change in average success rate across the sample period. Some of the variation between sample days could be explained by the random assignment of treatments. This resulted in some days having a higher proportion of "easy" trials compared to some days with more "difficult" trials (e.g. more trials involving 2 cache sites compared to more trials with 4 cache sites). To account for this the regression analysis was conducted using the success rate minus expected chance rate for each trial.

\section{Time of Day}

On some days two trials were conducted with each bird, with the two trials being separated by a period of at least two hours. This resulted in one set of trials being conducted in the morning and the other in the early afternoon. An independent samples ttest indicated that this did not have a significant effect on the birds accuracy in recovering the artificial cache sites between the two time periods $(T=-1.528, P=0.127)$. 


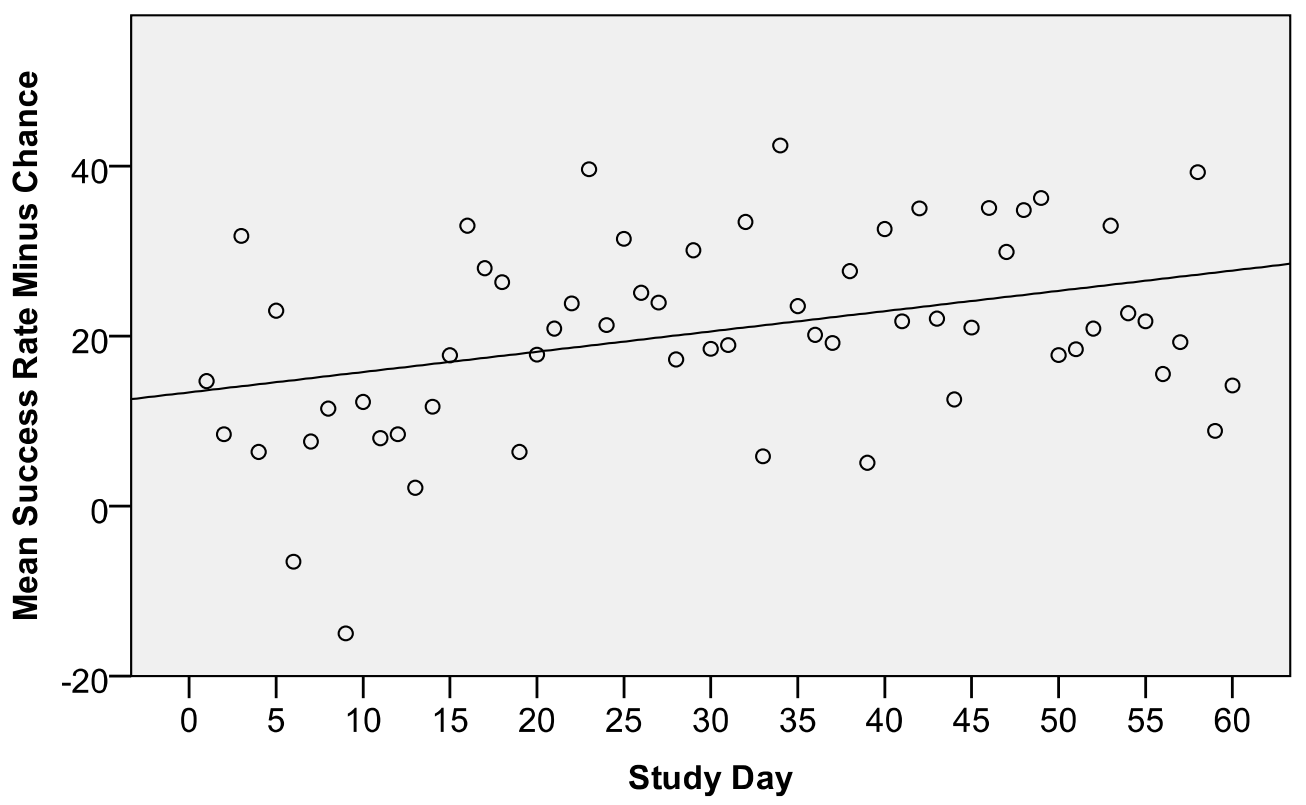

Figure 8: Percentage of 'correct' choices across all trials over the sample period. $Y=0.239^{*} X+$ 13.38

\section{Site Bias}

A chi-squared goodness of fit test was used to test for potential cache site bias or orientation preferences (i.e. whether one cache site was preferentially selected over the others available). None of the three levels of cache sites (2, 3 or 4 sites) showed orientation preferences for a specific site $(P>0.089$ for all trials $)$. 


\section{Chapter Three}

\section{Discussion}

\section{Observational Spatial Memory in North Island Robins}

The three experiments detailed here provide evidence showing that North Island robins are capable of utilizing observational spatial memory over at least short time periods. Overall they performed at above-chance expectation across the three sets of experiments. Some treatment combinations were not above chance (Fig. 6), but generally success decreased in a directional fashion as the complexity of the treatment increased. Treatments with a larger number of artificial cache sites would be expected to construe more of a memory challenge, as the birds must discriminate between a larger number of possible locations. Similarly, longer time frames are likely to reduce success rates as a result of temporal memory decay. Although not all treatment combinations were significantly above chance, the observed success rates were still all above chance level. The level of error within each treatment was high, as indicated by the error bars (Fig. 6). This is an unfortunate side effect of field trials, but could have been reduced through either a larger sample size or by running each independent variable as a separate experiment, rather than as a crossed model.

To date observational spatial memory has not been demonstrated in a non-corvid avian species (Emery \& Clayton 2004). This study presents the first instance of another avian order with this cognitive ability. This finding is interesting, not only because it represents an incidence of parallel evolution of a cognitive trait, but also because New Zealand robins do not display many of the features which have been hypothesised as mechanisms behind the development of OSM. Both sociality and high cache dependence have been posited as potential drivers in the evolution of OSM (Bednekoff \& Balda 1996b; a; Scheid \& Bugnyar 2008). Despite not possessing either of these traits, robins show OSM over short time intervals, suggesting other pressures may have been influential in the evolution of this cognitive adaptation. 
Intra-pair competition for resources may have been a driving force behind the evolution of observational spatial memory in North Island robins. Intra-pair resource competition in robins is intensive, especially during the winter (Steer \& Burns 2008; Menzies \& Burns 2010), with males being aggressive and competitively dominant over food resources (Alexander et al. 2005; Burns \& Steer 2006). In order for females to compete for an adequate share of resources they utilize increased pilferage as an alternative foraging strategy (Menzies \& Burns 2010). This is especially true over the winter months when males do not perform nuptial feeding. Female robins pilfer or recache male-made caches at a rate of nearly twice that of males pilfering female caches (van Horik \& Burns 2007). Despite this, female caches are still as likely to be pilfered by the male as they are to be recovered by the female who created the cache (van Horik \& Burns 2007).

Robins cache food which is of high energy value but may also be of high cost to obtain. For example tree weta (Hemideina spp.), which form part of the robins diet, and which are likely to be partly cached due to their large size, have powerful mandibles and are able to defend themselves aggressively. Bites are not only painful, but they risk becoming infected and may decrease foraging ability, making tackling prey more costly. There are also time and energy costs associated with dismembering and transporting large prey for caching. This may make pilfering a more profitable strategy, as these costs are borne by the thief's mate, allowing the pilferer to directly benefit from eating the cached items or expending only a relatively small amount of energy recaching. Pilferage by individuals who also cache their own food items has been proposed as an evolutionarily stable strategy (Vander Wall \& Jenkins 2003) as a thief's own caches are made available to the original storer through reciprocal cache theft (Dally et al. 2006).

Kamil and Gould (2008) note that there is a negative relationship between the cognitive demands of a cache recovery strategy and resistance of the strategy to competitors for the caches. Under conditions of high cache loss, increased cognitive abilities may be favoured despite the large metabolic costs cognitive abilities incur. The high level of cache loss and reciprocal cache pilferage in robins may have provided the necessary conditions for OSM to evolve, possibly driven by intraspecies sexual competition. Advances in OSM ability in one sex would likely be also conferred on the other sex over time, and an evolutionary 'arms race' for better pilfering systems to reduce the impact of cache loss from pilfering could arise. 
Close social interactions between members of a pair may also provide the necessary social experiences for OSM to develop.

Given that New Zealand robins do not fulfil the hypothesised ethological confines for OSM, sociality and high levels of cache dependence, their memory abilities as displayed in this study appear to be more sophisticated than we had initially anticipated. Essentially the range of variables tested was not wide enough to encompass the true limits of the robin's observational spatial memory abilities. This is surprising as pilot studies had shown the birds performing at close to chance level when presented with three cache sites. The pilot was conducted with only a small number of birds and consisted of fewer trials which may have skewed the results. Additionally some juvenile birds were used during piloting which may have led to a lower overall success rate. These individuals were later excluded from the final studt. Retention intervals were deliberately kept short as previous studies and observations suggested that most pilfering in robins occurs within a few minutes of cache creation (van Horik \& Burns 2007). This study also included the use of a variable reward to test for not only OSM ability, but also to investigate the robins' ability to make numerical judgements regarding pilfering activity. This is a novel feature of this study, as it shows that North Island robins are capable of sophisticated decision making regarding cache selection, even when required to rely on memory.

Unlike the majority of observational spatial memory studies, the experiments documented here were conducted in the field as opposed to in a laboratory or aviary. The amount of variability in both the environment and between individual study subjects during field experiments would be expected to produce more noise in the data than under laboratory conditions where external variables can be carefully controlled. One of the difficulties in animal studies is controlling for variation between individuals. This is especially true when utilizing wild animals compared to hand-reared specimens, as it is usually not possible to standardise past experience. Individuals varied in their accuracy in making successful choices (Fig. 7), although this did not appear to relate to the age of the bird. This variation is to be expected as all populations vary behaviourally and cognitively, as well as morphologically. Variation in OSM success may be innate and inherited or may result from differences in learning and experience. Individual differences were standardised to some extent by using all paired adult males outside of their hatch year, and the results here suggest that differences 
between individuals was not significant. All these males had previously been used in a variety of other studies involving similar methodologies and so none were experimentally naive at the beginning of the trials.

Hunt et al. (2008) found that robins did not preferentially choose cache sites containing prey if they had not been given the opportunity to watch the prey being hidden. This strongly suggests that it is not simply factors such as smell and sound which the robins are using to locate prey. This is supported by the fact that robins hunt through predominantly visually methods, such as gleaning and scanning (Powlesland 1981b). Hunt et al.'s (2008) study used human demonstrators and hidden prey to demonstrate that robins were able to make numerical judgements about an event they had observed. This ability to observe an event and apply appropriate behaviours suggested that observational spatial memory could be a possibility in robins. Hunt et al.'s (2008) study also demonstrated that robins possess objectpermanency, and are able to remember objects which are outside of their immediate line of vision. This is essential in a species which uses spatial memory to recover caches, rather than relying on recovering them during daily foraging activities. While the area of spatial memory in robins has not yet been explored it seems almost certain that they rely to some extent on spatial cues to locate their caches. Both parids and corvids, the two most intensively studied groups, use spatial memory for accurate cache recovery (See Clayton 1998 for a review).

\section{Number of Cache Sites}

Experiment 2 was the only experiment where there was a significant difference in success rate between the number of sites. In this instance it was the two-site trials which had the higher success rate (Fig. 4a), i.e. the less complex treatments. However trials involving three or four cache sites still produced above chance success rates. The number of cache sites selected for these experiments was based on the average number of individual cache sites which a robin will generally maintain at any one time. This is usually between one to three different cache sites (van Horik \& Burns 2007), but occurs only when presented with a superabundant amount of prey. Male robins usually create fewer caches than females (van Horik \& Burns 2007) as they are more able to aggressively defend them. Conversely females are more likely to adopt a scatter-hoarding system, creating more separate caches and spacing them 
further apart. The fact that number of cache sites was non-significant in two of the three experiments here shows that robins are capable of distinguishing between a larger number of locations than the maximum of four sites used in this study. This suggests that robin's possess the ability to track more locations than they may typically utilize for their own caching needs. However it should be noted that, while the robins created three or less caches when presented with a large supply of food items by van Horik and Burns (2007), this does not preclude the idea that under natural foraging conditions the birds may utilize more separate caches sites located throughout their territory. If this is the case then robins would be expected to have better site discrimination abilities than was predicted for the study reported here.

Increased memory load can cause an increase in interference in memory retrieval. This may result either from memories that were created beforehand (proactive interference) or from memories that are created afterwards (retro-active interference) (Smulders et al. 2010). The larger the number of locations an individual needs to recall, the greater the chance of memory displacement or retrieval interference. Being able to recall more separate locations than the robins require for their own caching needs would be a useful memory component for observational spatial memory. It would allow an individual to monitor the locations of caches belonging to others without the risk of displacing memories for their own cache sites.

Ultimately, retrieving an individual's own caches is more likely to be advantageous than relying on recalling the locations of those caches made by others. When pilfering other individuals' caches there is a possibility that a cache may have already been recovered by the owner. This results in wasted time which could otherwise be used more productively in foraging or other maintenance activities. Additionally, increased interference in memory retrieval as more locations are required to be remembered could result in a decrease in locating one's own caches. For this reason memory for another individual's cache sites is likely to only be advantageous if there is no detriment to the memory of the locations of their own caches.

The experimental apparatus used in this study was based on that used by Hunt et al. (2008) for previous work with robins. This had showen that this methodological construct worked appropriately for conducting choice experiments with robins. The artificial cache sites in this 
study were not close analogues to natural cache sites used by North Island robins. The artificial site were much closer together than most natural robin caches and so required finer observation in order to discriminate between them. Robin caches are also often located in a wide variety of substrates and locations. While branch-trunk axils are most commonly used (Alexander et al. 2005) caches may also be located in tree fern fronds and trunks, depressions in branches, and among detritus accumulated on horizontal branches (pers. obs.). Because the apparatus used to represent artificial caches was comprised of a single branch, it had less landmark cues than robins would typically have available to locate their own cache sites. This further increases the complexity of the task by reducing the number or type of cues which can be relied on for visual orientation of the correct cache. As a result the apparatus was perhaps more similar to a foraging task, with the birds locating insects hidden under ground debris, than to a true cache recovery task. While the artificial cache sites in this study did not explicitly include enhanced local landmarks, such as Clayton and Dickinson (1998) used, the branches did have natural variation which may have assisted in site discrimination. If this is the case then the lack of proximal cues in this study may not have a major influence in the ability of the birds to recover the experimentally hidden of prey. Additionally, if global landmarks are more important, then conducting the trials in the same locations within the bird's territory should have allowed the birds to use familiar global landmarks. Currently there is no literature on understanding the mechanisms by which robins locate and recover their caches. It seems likely that they rely on spatial cues supported to some extent by both proximal and distal landmarks when returning to a cache site. Object-specific landmarks are also subject to change. Branches may break, leaves fall off trees and ground cues can be covered with snow or mud. Because of this, other reference systems may be more valuable for locating cache sites, especially over long time frames (See Sherry 1992). However, this study was intended to investigate whether the birds could locate sites where they had observed another individual hiding prey. In this regard the methods used were suitable, even if not naturalistic.

Most corvid studies look at number of errors made before successfully recovering a cache. This was not a practical solution for this study due to the low number of artificial cache sites used. There is a possibility that if allowed to open as many caches as they wanted the birds would have no incentive to make a decision relating to cache choice. The low number of cache sites meant that they could simply open all the caches until the mealworms were 
located. The small number of sites presented, and the close proximity to each other would incur only a small time or energy cost which would be easily met by the mealworm reward.

Because robins do not cover or hide their caches there is less need for a high level of accuracy when observing a caching event. While robins create caches at higher levels in the canopy than they forage (Powlesland 1980), they can easily return to this height if they are intending to recover or pilfer a cache. Because they often pilfer within short time periods of observing the caching event (van Horik \& Burns 2007), they may be able to use a memorydirected search pattern in the area where they observed the caching event rather than recalling the exact location of the cache. It is possible that a pilfering robin may only remember the general location and then rely on visually locating the cache once they are there. This would require less high-accuracy memory than locating buried caches such as many corvids make. In these instances a beak probe which is off by only a few centimetres would fail to locate a hidden food item.

\section{Retention Interval}

Memory traces decay over time and longer periods between caching and recovery or pilfering would be expected to lead to a corresponding decrease in success rate either through a reduction in memory accuracy or an increase in search errors. The retention intervals in these experiments were deliberately kept short as the study was designed as a test of observational spatial memory, rather than to determine how these memories decrease with time. The effect of retention interval is difficult to interpret from this study as retention interval was only significant in Experiment 3, which offered a maximum of three mealworm prey items. In this experiment the longest 60 second trials had a lower success rate than the 0 or 10 second trials which did not differ significantly from each other.

Despite the general lack of significance there does appear to be some trends across retention intervals (Fig. 4b). In Experiments 1 and 2, 0 second trials had a higher success rate compared with trials with a 60 second retention interval, although this was not statistically significant. Trials with a 60 second interval however, were still above the level of chance. This may suggest that while accuracy may decrease somewhat over a period of 60 seconds, 
this is still within the memory capabilities of North Island robins. However the 0 second trials were also methodologically different from the longer retention intervals as they did not involve the cache sites being occluded from view. In this respect the 0 second trials were not a test of memory and so are not directly comparable to the other retention intervals.

A decrease in accuracy over comparatively short periods should be predicted by current knowledge of robin caching behaviour. Cache recovery by robins is usually on the same day that the cache is created, and always within three days (Powlesland 1980). Pilfering on the other hand usually occurs over shorter intervals of less than 30 minutes (van Horik \& Burns 2007), and often within a few minutes of caches being created (pers. obs.). The fact that the retention interval of 60 seconds has a significantly lower success rate in trials with 3 mealworm prey seems to suggest that $60 \mathrm{sec}$ is near the robin's maximum limit when tracking larger numbers of prey. However this does not explain the fact that in this study the birds would only need to track the one correct cache site irrespective of the number of prey items being hidden. This may simply be an artefact of the study or there may be other mechanistic explanations behind it. Given the short intervals between caching and pilfering attempts in robins, the 60 second treatment is not an unreasonable limit. This study posed more of a cognitive challenge than pilfering caches made by other robins due to the close proximity of sites to each other, the fact that the apparatus was covered with a sheet and the contents of the caches being obscured by flaps. It is probable that with more naturalistic caching trials the actual limit of the robins OSM retention would be significantly extended.

These retention intervals used in this study are significantly shorter than those of the corvid and parid species which currently make up the majority of the literature on OSM. Parid studies used retention intervals ranging from six minutes to two hours (Baker et al. 1988), while corvid studies covered a wide range of intervals, from five minutes to seven days (Bednekoff \& Balda 1996b; a; Bugnyar \& Kotrschal 2002). However these species are predominantly long-term hoarders which rely on cached food for significant proportions of their winter energy requirements. The shorter retention intervals used in this study were more ecologically relevant for robins given the time periods over which most of their cache recovery and pilfering activities take place. It should be noted however that Scheid and Bugnyar (2008) also used a one minute retention interval for ravens and jackdaws. Of the current literature in the observational memory area, Scheid and Bugnyar's study is 
methodologically closest to the study presented here. Short retention intervals were used, along with small numbers of artificial cache sites (between 2 and 10) and the birds observed a human experimenter hiding food items rather than a conspecific.

While treatments with no retention interval ( 0 seconds) generally had the highest success rate (Fig. 4b), these are not directly comparable to trials with 10 or 60 second retention intervals. Trials with longer retention intervals required that the experimental apparatus be covered to obscure it from view, which did not occur with the 0 second trials. As a result the two sets of treatments are not directly analogous. By not removing the apparatus from the bird's line of sight, they were not required to actively memorise the correct cache location. As a result the 0 second trials are a test of observation, but not necessarily observational memory. When the apparatus was not obscured the bird had the option of maintaining continuous visual contact with the cache site where they had observed the mealworms being placed. Upon being given access by the experimenter the bird would not have to 'remember' the correct location but would be able to simply access that cache it had been watching. From observing the birds this did not appear to be the case, as they are often active during the experiment and do not appear to continuously observe any one location. Regardless, this cannot be ruled out in the 0 second trials where the apparatus was not obscured from their view.

Retaining continuous visual would not necessarily be an appropriate tactic for raiding another robin's cache, as the storing individual would be likely to detect such an obvious technique and modify their caching behaviour accordingly. Male robins will aggressively defend their caches from females (van Horik \& Burns 2007) when caching in close proximity, suggesting that more 'strategic' pilfering behaviour should be favoured. Other bird species, especially corvids, have been shown to adjust their caching behaviour in the presence of conspecifics. Ravens prefer to cache out of sight of other individuals, either by moving further from the food source or by caching behind obstacles which obstruct views. When this is not possible they will delay caching or attempt to cache when the other individuals are distracted (Heinrich \& Pepper 1998). Bugnyar and Heinrich (2006) also demonstrated that when ravens were allowed to retrieve by themselves, the observer quickly located and pilfered other individual's hoards. However when allowed to recover with a dominant individual still present the observer took significantly longer before attempting to pilfer the cache. Not only that, but the observing bird also made more searches in areas away from the cache sites 
before attempting to pilfer when the owner of the cache was present. This suggests that not only does the pilferer delay attempts at theft in situations where there may be aggressive ramifications, but that they also withhold their intentions and attempt to manipulate the behaviour of the storing bird by deliberately searching in locations away from known cache sites. Similar changes in caching behaviour while being observed have also been shown in other corvid species such as pinyon jays (Bednekoff \& Balda 1996b), scrub jays (Dally et al. 2005) and gray jays (Burnell \& Tomback 1985). Scrub jays are also able to keep track of whether they are being observed or not during a caching event and use this information to decide whether or not to re-cache items at a later date. Prior experience as a thief seems to be necessary for this behaviour to develop (Emery \& Clayton 2001) which suggests that social experience is important for advanced cache protection strategies to arise.

Bugnyar and Kotrschal (2002) also noted that the ravens used in their study began pilfering attempts between one and two minutes after watching the caching event. This suggests that even in ravens, which have been shown to possess accurate and flexible observational spatial memory abilities (Bugnyar \& Heinrich 2006; Heinrich \& Pepper 1998; Scheid \& Bugnyar 2008), pilfering is still conducted soon after witnessing caching. In situations where there is a large amount of food available, pilfering soon after the caching event may be advantageous as it is likely that, after creating one cache, the storer will continue to create more caches in different locations for as long as the food source persists. During this period of caching the individual may be distracted from monitoring the first cache it created, thereby allowing a window in which pilfering can safely occur. Robins cache in a highly complex temperate rainforest, as opposed to in more open environments. This provides many opportunities for a potential thief to be out of sight and thus able to recache items with a reduced risk of being noticed. This would be expected to reduce the incentive to develop longer-term pilfering strategies as short-term approaches may be equally effective, without the need for more advanced cognitive abilities.

Long-term observational spatial memory is not necessary if there is a chance to pilfer another's cache directly after the cache is created. Short intervals between caching and pilfering, however, mean that there is a greater chance of the creator of the cache still being in the vicinity. This could lead to aggressive encounters which are generally non-adaptive to both parties and to be avoided. For this reason observational spatial memory is advantageous 
as it allows a potential thief to benefit from increased accuracy in recovering others caches, while allowing them to reduce the potential negative repercussions. Being able to utilise OSM for pilfering allows for more flexible cache raiding techniques as it is not necessary for a pilferer to displace the owner of the cache, as they are able to delay their pilfering until the owner has left the scene (Bugnyar \& Kotrschal 2002). Because robins are not totally dependent on cached food items for long-term resource provision there is likely to be lower fitness consequences of not remembering a cache location than for a species which relied almost exclusively on food-hoarding to supply its winter energy demands. From an evolutionary point of view this would reduce the selective pressure to develop advanced, long-term spatial memory systems with regard to food hoarding.

In robins, competition for cached resources is most intense during the winter months (Steer \& Burns 2008). During this time territories are largely sexually segregated with each member of a pair defending a portion, resulting in less joint foraging (Menzies \& Burns 2010). This is also the period when pilfering would be most advantageous, especially for females. During summer insects are plentiful and females can generally rely on having a significant proportion of their energy requirements met through nuptial feeding by their mate (Powlesland et al. 2000; Steer \& Burns 2008). However during winter insects are both less plentiful and also less active, making hunting more difficult and time consuming. These conditions make pilfering as a supplementary foraging tactic more likely to be advantageous during these months. A possible side effect of territory segregation may be to increase the need for 'stealthy' pilfering strategies as individuals will often aggressively defend their section of a territory even from their own mate. It is possible that fast recaching, after only a short retention interval could allow a robin to move items into its subsection of the territory and return to foraging without spending significant periods of time encroaching on its mate's territory. Short retention intervals before recaching also ensure that prey items are not decayed, recovered by the owner, or pilfered by another individual (either its mate or a heterospecific (Steer \& van Horik 2006) as other robins generally avoid intruding on neighbouring territories).

If birds are relying on OSM to locate others caches then it should be paramount to avoid being observed during caching. This is less important if cache theft is based on other cues such as olfactory, visual searching or searching near preferred landmark types. Robins cache 
less in the presence of conspecifics (Burns \& Steer 2006), and make different decisions regarding caching when alone compared to caching in the presence of another individual (Burns 2009; Steer \& Burns 2008). Apart from a slight reduction in caching behaviour when in the presence of its mate (Burns \& Steer 2006), male robins do not appear to utilize many strategies to avoid females observing their cache locations. Even black-capped chickadees show some cache protection strategies, such as flying further from their companions when caching (Hitchcock \& Sherry 1995). This is despite chickadees not appearing to possess observational spatial memory (Baker et al. 1988).

This lack of tactical cache creation by males is surprising, as the high levels of pilferage observed among robins would suggest that cache protection strategies should have evolved. Males will aggressively defend their caches from their mates (van Horik \& Burns 2007), however this tactic is only effective for as long as the male stays in the immediate vicinity. Reciprocal cache pilferage can account for some lack of cache protection, as stealing from others may be used to recover energy deficits as a result of having one's own caches stolen. However any individual which developed some form of cache protection would be expected to outperform those individuals which don't protect their caches. This trait should then become widespread within a population and the fact that this does not appear to have occurred is certainly interesting. Possibly because robins do not risk high levels of cache theft from individuals (either con- or hetero-specific) other than their mates, and they benefit genetically from having a healthy mate, this species may be able to tolerate higher levels of pilferage than flock foraging species where kinship is low and there is no direct benefit from cache loss. The presence of other individuals (either the study bird's mate or another individual) was not recorded in this study and it is possible that this may have impacted on the birds' cache retrieval decisions.

Robin caches are opportunistically stolen by Hihi (Notiomystis cincta) and Saddleback (Philesturnus carunculatus) (Steer \& van Horik 2006), as well as by their own mates and possibly offspring. This suggests that robins should adopt different caching strategies when there is a possibility of being observed by any other individual. Hihi and Saddlebacks do not cache themselves and they are more likely to pilfer caches which they chance upon while foraging rather than carrying out deliberate theft. It would be interesting to discover if robins perceive human experimenters as equivalent to conspecific caching individuals and assign 
possible motive as a thief. Given that none of the studies conducted with these robins to date has involved cache protection or pilfering by the human demonstrator, the robins may not feel that they need to display the same pilfering tactics that they would when observing a conspecific.

\section{Effects of Reward}

The total number of mealworms presented had an effect on the accuracy with which the robins were able to locate the hidden prey. Experiment 1 where the birds were only offered one mealworm had the lowest average success rate (mean $=51.39 \%$ ), where as Experiment 3 , involving three prey items, had the highest average success rate (mean $=59.72 \%$ ). This difference was significant between the first experiment and the second and third experiments, but not between experiments 2 and 3. Hunt et al. (2008) conducted a series of experiments with robins which accounted for the potential confounding effects of the amount time taken to fill each cache site with different numbers of prey items as well as for the volume of items in the trial. Both of these factors were found to be non-significant, meaning the robin's ability to choose larger quantities is not related to either of these variables. There is no indication that this should be different in this study.

Without further research it is not possible to say definitively what the reason behind this number discrepancy is. The experiment where the birds were only offered 1 mealworm would appear to construe less of a cognitive challenge than the other two experiments. Experiments 2 and 3 contained a variable reward which necessitated discrimination between the larger number of mealworms and the lower value reward. This makes the lower success rate for experiment 1 surprising. The lower success rate in trials where only one mealworm was presented may simply be an artefact of the experimental design. It is impossible to be certain that the birds are attending to the experimenter while the mealworms are being presented and hidden. It may be that when only one mealworm was used then birds were distracted for enough trials that they did not see which site the item was cached in. When more than one mealworm was being presented a momentary distraction would be less significant as there would be further opportunities to see where the correct site was. In order to minimise distractions the trials were only conducted when the birds were less than two metres away 
and were halted if the bird appeared to not be watching the demonstration. Additionally the mealworm/s were held up and displayed to the bird prior to being placed in the artificial cache to ensure the subject had an adequate view. This however does not guarantee that the subject was sufficiently attentive, or that it was engaged in memorising the location.

Accurate discrimination between sites containing variable numbers of items may be important when pilfering from caches which are located close together. Obtaining the highest available reward would make pilfering a more viable strategy if there is the possibility of aggressive repercussions from a mate or other individual. In Experiments 2 and 3 the birds selected the cache sites containing the lower value reward at levels significantly below that predicted by chance. This strongly suggests that the birds were actively avoiding these sites in favour of the sites containing the larger number of mealworms, which were selected at above-chance levels. Hunt et al.'s (2008) study showed that robins are capable of accurate numerical discriminations of up to, and possibly over 12 items. Neither Hunt et al. nor the study presented here used simultaneously visible sets of items, which meant that the birds were required to accurately observe and record the number of items being hidden. This is a more complex, but likely more naturalistic cognitive challenge than discriminating between visible sets of objects. Appropriate use of OSM requires that an individual observe caching behaviour from a distance in order to avoid alerting the cacher to the pilferer's intentions. This would require an individual to maintain an accurate representation of the number of items observed being hidden in several different locations. Prioritizing the pilfering of the cache containing the largest quantity of prey would allow a pilferer to maximise energetic rewards gained during short temporal opportunities while the cacher is not in the vicinity.

An interesting line of further study would be to look at the value of incentive in altering choice behaviour. One mealworm may be deemed 'low reward' in regards to participating in the trial. Low incentive may have led to less active participation in the memory and decision making process by the robins. If the birds deemed one mealworm as low reward then there may have been reason to actively choose to open another cache in which they had not observed the mealworm being hidden in, believing that there was a possibility of higher reward elsewhere. This idea of 'gambling' a certain but low value reward against the possibility of a less sure, but possibly higher value reward is speculative but intriguing. It 
may be possible to investigate the importance of differing numbers of items versus reward incentive by using the same number of two types of item which differ in reward value.

\section{Temporal Variation in Success Rates}

While change over time was not a salient component of this study, these results show no significant change in success rate over the study period, despite it covering winter through to late spring. Many Northern Hemisphere species show pronounced peaks in food hoarding behaviour with the onset of autumn (Shettleworth et al. 1995; Clayton et al. 1996; but see Pravosudov 2006). These species generally rely heavily, or even exclusively, on cached food to meet their winter energy demands. New Zealand robins cache year round, however there is a significant decrease in caching behaviour over the breeding season between September and March (Powlesland 1997). Males typically begin nuptial feeding of their mates around early September and this coincides with a drop in caching behaviour (Steer \& Burns 2008). The reduction in caching behaviour during the breeding season is a result of surplus food being mostly used for nuptial and offspring feeding, rather than because of a seasonal reduction in the incentive to cache (Menzies \& Burns 2010). Seasonal changes in food-hoarding intensity are also thought to result in seasonal changes in the underlying neural substrate which mediates memory for stored food. The hippocampal formation in aves has been implicated as the neural centre for a variety of memory functions, including spatial memory (O'Keefe \& Nadel 1979; Sherry \& Vaccarino 1989; Krebs et al. 1996; but see Brodin \& Bolhuis 2008).

If winter hoarding in robins was associated with a seasonal improvement in spatial memory, then the trend across this study would be expected to show a decrease in success rate towards the end of the sampling period to coincide with the period of reduced caching intensity during the breeding season. Chickadees show an increase in hippocampal volume in autumn (Smulders et al. 1995; Smulders et al. 2000) which is thought to relate to the onset of winter food hoarding. Because robins cache at any time when they have a surplus of food, spatial memory in robins, as it relates to food caching, would not be expected to be as seasonally dependent. In addition, black-capped chickadees are not territorial whereas robins maintain strict territories year-round. Territoriality is another area where spatial memory is crucial, and would be expected to have led to a year-round necessity for accurate spatial memory in 
robins. As a result robins would be expected to have less seasonal variation in either hippocampus volume or spatial memory ability.

Rather than showing a decrease in success rate as caching intensity declines, the linear trend (Fig. 8) seems to show the opposite, with a very slight increase over this time period, contrary to what would be expected if there was a decrease in spatial memory associated with decreased food hoarding behaviour. The first few study days show a lower degree of success compared to later days. There was no initial training period for the birds prior to the start of the study. This meant that the birds were required to learn the 'rules' of the study, such as only being allowed to open one cache site, during the trials themselves. This may account for the lower levels of success over these first days. The random designation of treatments in the study was designed to reduce the effects of learning on the likelihood of a successful outcome.

Healy et al. (2005) suggest that increased hippocampus volume may be related more to the duration of memory rather than to other aspects of memory associated with cache retrieval. Robins only need to retain memories of cache location for relatively short periods until retrieval. However as North Island robins utilize the same caches within their territories repeatedly, they may retain memories for the location of the sites long term, meaning they only need to remember whether the cache currently contains food, what the contents are, and perhaps how long ago the items were cached. These are all cognitive elements which could warrant further investigation in robins. An analysis of robin hippocampal volume in comparison to a closely related, non-caching, species such as the tomtit (Petroica macrocephala) could provide interesting details on the neural structure underpinning the behaviours investigated in this study.

Despite food-hoarding appearing to be an innate rather than learned behaviour (Clayton 1992; 1994; 1996), there is still a level of experience required in order for appropriate and accurate caching and pilfering strategies to develop (Clayton 1994; 1995; Emery \& Clayton 2001). While there is currently no literature on when caching behaviour begins in robins, most natal feeding is performed by the male, with male caching behaviour decreasing to close to nothing during the breeding season (Menzies \& Burns 2010; Steer 2006). This means there is likely to be little opportunity for fledglings to observe caching behaviour while still on the parental 
territory. Caching experience is therefore likely to be gained once outside of their parent's territory given the short period of parental investment after fledging. This study attempted to remove this experience bias by using only paired adult males who had already gone through at least one breeding season. 


\section{Summary and Conclusions}

North Island robins display observational spatial memory for cached food items across at least short time periods. To date this behaviour has only been documented among species of the family Corvidae (Bednekoff \& Balda 1996b; a; Bugnyar \& Kotrschal 2002; Scheid \& Bugnyar 2008), making this the first study to show another avian species with this cognitive ability. New Zealand robins do not display many of the ecological traits which have previously been hypothesised as mechanisms which may driven the evolution of OSM in other species. They do not cache in high volumes (Alexander et al. 2005; Menzies \& Burns 2008; van Horik \& Burns 2007) and are not cache dependent for winter survival (Menzies \& Burns 2008; Steer \& Burns 2008). Additionally robins are not highly social and so have limited opportunities to interact with conspecifics, and thus gain experience in social interactions.

Because of the memory demands of locating cached food, hoarding behaviour is physiologically expensive as it requires the development of neural and cognitive faculties to deal with this increased memory load. Time and energy expenses of food hoarding behaviour mean than an individual must recover most of its cached food in order for the behaviour to be adaptive (Vander Wall 1990). If there is a high chance of the stored food being lost, either to a conspecific or interspecific competitor, then other strategies should be employed. These may be either minimising the chance of cache loss through consuming more food items immediately and caching less, or employing tactical decisions to reduce the chance of caches being found. An alternative strategy is to utilize behaviours which increase pilfering from caches created by other birds, as this can compensate for food lost from an individual's own 
caches. Tolerating relatively high levels of cache theft by their mates may be a form of indirect mate provisioning by male robins (van Horik \& Burns 2007). Aggression in males may be necessary in order for them to maintain a territory, and hence may be seen as a positive trait by females, even if it is directed towards them during competition for food. A high level of pilfering by females is a way in which they can overcome the disparity in resource acquisition without challenging the males directly.

Traditionally avian species such as pigeons and chickens have been used only as models of associative learning. More recently a body of research involving corvids and psittacitformes has shed some light on more complex cognitive behaviours (Emery, 2006; Emery, 2004). Robins provide a new avian model: small passerines which nevertheless are capable of displaying more sophisticated cognitive abilities than traditional avian models. While many of the robins cognitive processes may not be as complex as those displayed by corvids or parrots, they may provide an interesting intermediate. Studies on robins could be used to shed light on the conditions necessary for these advanced cognitive abilities to evolve. New Zealand robins do not display either high levels of sociality or cache dependence, the two traits hypothesised to be mechanisms leading to OSM evolution in corvids. This suggests that there are alternative pressures which could drive the evolution and development of this trait, at least in North Island robins. Intensive intra-pair competition for resources, characterised by high levels of reciprocal cache theft can be proposed as a possible mechanism leading to advanced cognitive traits which improve pilfering strategies.

Within robin pairs there is intense competition between mates for resources, especially in the non-breeding season. This intra-pair competition may have driven the evolution of OSM in robins through sex-related differences in resource acquisition. Males are competitively 
dominant in gaining access to resources year-round. As a result females may have developed OSM as a counter tactic, allowing for more successful pilfering of male-made caches, and thus reducing the discrepancy in overall resource consumption between sexes. OSM in males would be expected to develop as a spinoff of this and allow males to recover some resources through reciprocal cache pilferage.

There will always be necessary methodological compromises when working with wild animals in the field compared to laboratory conditions. One area in which this study was lacking was the use of a sheet to occlude the experimental apparatus. Ideally the whole apparatus should be removed from the birds view, rather than just covering it. This is easily done in a laboratory setting where the apparatus can be removed from the bird's cage, but is not easily reconstructed in a field experiment. Removing the whole apparatus would require longer retention intervals and it would be necessary to ensure that it was removed entirely from the bird's territory and that they were unable to see it. Additionally when the apparatus was returned it would need to be positioned and oriented in the exact location and setting as when the demonstration was carried out to ensure that all available landmarks were consistent. One way in which this could be overcome would be to use a similar apparatus, but in which the artificial cache sites were able to be locked to prevent the birds accessing them. This would allow the apparatus to be left in place for longer periods without changing the surrounding cues. 
The study presented here could be used as a guide for additional research on any of the variables tested. Further expanding on the variables tested here would be necessary in order to accurately delineate the memory abilities of North Island robins. Longer retention intervals could be used, although there would be some issues associated with retaining the bird's focus which would need to be overcome. Given the comparatively low numbers of cache sites utilised by robins, including those used by their mates, increasing the number of cache sites would not seem be ecologically relevant and would provide little more information on the abilities of robins to use OSM. The ease with which naive New Zealand robins can be enticed into participating in experimental procedures allows for a wide variety of ecological and cognitive experiments to be conducted in completely natural surroundings.

\section{Future Research}

\section{Sex differences}

Many aspects of spatial memory are associated with sexual dimorphism in regards to ability. Males and females of any species often differ not only morphologically, but also behaviourally and cognitively. This often relates to differences in evolutionary pressure over time favouring the development of sexual dimorphism in traits which confer a selective advantage to either sex. Spatial memory is thought to be one of these traits, and males of a wide variety of species often outperform females when tested on spatial memory tasks (Gresack \& Frick 2003; Kavaliers et al. 1998; Maguire et al. 1999; Galea et al. 1994). The reason for this is still not fully understood (Healy et al. 2009) and a number of alternative hypotheses have been suggested to explain this trend, the most plausible of which is the 
'range size hypothesis' (Jones et al. 2003). This relates to the idea that male territory size is often significantly larger than that of females and males are also more likely to be responsible for the majority of territorial defence. For this reason males need to have an accurate spatial awareness of the boundaries of their own territory as well as the boundaries of territories belonging to neighbouring males.

Male and female North Island robins share the same territory year round, as a result range size does not differ between sexes in this species. The majority of territorial defence (i.e. singing and aggressive displacement) is carried out by the males, however females will also sometimes actively chase intrudes from their territory (pers. obs.). In regards to pilfering, female robins rely on this behaviour significantly more than their male counterparts. While both species cache food a similar rates, male-made caches are more than two times more likely to be retrieved by the female than by the male who made the cache. By contrast female-made caches are recovered at the same rate by both the male and female of the pair (Burns \& van Horik 2007). This dichotomy in pilfering rates may have led to the evolution of sexually dimorphic OSM abilities, with females out performing males in this aspect of spatial memory. If this were the case it would be of significant interest and may shed further light on the reasons for male-dominated spatial memory in other aspects.

\section{Age}

Pilfering using observational memory involves some understanding of the motives and potential reactions of other individuals. Because of this there would seem to be an element of experience and learning required in order to fully develop this ability. This suggests that age may play an important part in determining success in trial of the kind conduced in this study. The population of birds at Zealandia offers the potential to follow individual robins over a 
series of years to determine any age-specific differences in spatial memory. Alternatively the current banded population offers a shorter term option of using cohorts of different ages to study comparative differences in observational spatial memory.

\section{Use of cues to locate caches}

There is currently a large amount of literature looking at the use of spatial and landmark cues in cache recovery, as well as their relation to other spatial memory tasks. Because robins maintain a year-round territory, they would be expected to have a good understanding of the global landmarks within their territory boundaries. However they also utilise a variety of cache sites such as branch-trunk axils, tree ferns, bark cavities and patches of accumulated detritus on horizontal branches. This variety of unique cache sites, and the fact that they do not attempt to cover or disguise their caches does provide the birds with a large number of local cues which could be used for cache recovery. Knowledge of which cues the robins are most reliant on would be interesting for its own sake, but may also be important for other future studies across a range of subjects to ensure the trials are conducted in a way which allows the birds to perform optimally. 


\section{References}

Agrillo, C., Dadda, M. \& Bisazza, A. 2007: Quantity discrimination in female mosquitofish. Anim. Cogn. 10, 63-70.

Alexander, L., Duthie, C., Fyfe, J., Haws, Z., Hunt, S., Montoya, I., Ochoa, C., Siva, A., Stringer, L., Van Horik, J. \& Burns, K. C. 2005: An experimental evaluation of food hoarding by North Island robins (Petroica australis longipes). Notornis 52, 138-142.

Andersson, M. \& Krebs, J. 1978: On the evolution of hoarding behaviour. Anim. Behav. 26, 707-711.

Armstrong, D. P. 2001: Sexing North Island robins (Petroica australis longipes) from morphometrics and plumage. Notornis 48, 76-80.

Armstrong, D. P., Raeburn, E. H., Powlesland, R. G., Howard, M., Christensen, B. \& Ewen, J. G. 2002: Obtaining meaningful comparisons of nest success: data from New Zealand robin (Petroica australis) populations. N. Z. J. Ecol. 26, 1-13.

Baker, M. C., Stone, E., Baker, A. E. M., Shelden, R. J., Skillicorn, P. \& Mantych, M. D. 1988: Evidence against observational-learning in storage and recovery of seeds by Black-Capped Chickadees. Auk 105, 492-497.

Balda, R. P. \& Kamil, A. C. 1989: A comparative study of cache recovery by three corvid species. Anim. Behav. 38, 486-495.

Balda, R. P. \& Turek, R. J. 1984: The cache-recovery system as an example of memory capabilities in Clark's nutcrackers. In: Anim. Cogn. (Roitblat, H. L., Bever, T. G. \& Terrace, H. S., eds). Hillsdale, NJ: L. Erlbaum Associates. pp. 513-532.

Basil, J. A. 1993: Neuroanatomical and behavioral correlates of spatial memory in Clark's nutcrackersDissertation, University of Massachusetts.

Bednekoff, P. A. \& Balda, R. P. 1996a: Observational spatial memory in Clark's nutcrackers and Mexican jays. Anim. Behav. 52, 833-839.

-. 1996b: Social caching and observational spatial memory in pinyon jays. Behaviour 133, 807-826.

Bednekoff, P. A., Balda, R. P., Kamil, A. C. \& Hile, A. G. 1997: Long-term spatial memory in four seed-caching corvid species. Anim. Behav. 53, 335-341.

Beran, M. J. 2001: Summation and numerousness judgments of sequentially presented sets of items by chimpanzees (Pan troglodytes). Journal of Comparative Psychology 115, 181191. 
Borkin, K. M., Goodman, A. J., Mayhew, K. \& Smith, E. 2008: South Island robin (Petroica australis australis) abundance and leaf-litter invertebrates in plantation and native forest. Notornis 54, 65-70.

Bossema, I. 1979: Jays and Oaks: An Eco-Ethological Study of a Symbiosis. Behaviour 70, $1-117$.

Brannon, E. 2005: What Animal Know about Numbers. In: Handbook of Mathmatical Cognition. (Campbell, J. I. D., ed). Psychology Press London.

Brodin, A. 2005: Mechanisms of cache retrieval in long-term hoarding birds. J. Ethol. 23, 7783.

-. 2010: The history of scatter hoarding studies. Philos. Trans. R. Soc. B-Biol. Sci. 365, 869881.

Brodin, A. \& Bolhuis, J. J. 2008: Memory and brain in food-storing birds: Space oddities or adaptive specializations? Ethology 114, 633-645.

Brodin, A., Lundborg, K. \& Clark, C. W. 2001: The Effect of Dominance on Food Hoarding: A Game Theoretical Model. The American Naturalist 157, 66-75.

Bugnyar, T. \& Heinrich, B. 2006: Pilfering ravens, Corvus corax, adjust their behaviour to social context and identity of competitors. Anim. Cogn. 9, 369-376.

Bugnyar, T. \& Kotrschal, K. 2002: Observational learning and the raiding of food caches in ravens, Corvus corax: is it 'tactical' deception? Anim. Behav. 64, 185-195.

Burnell, K. L. \& Tomback, D. F. 1985: Steller's jays steal gray jay caches: Field and laboratory observations. The Auk 102, 417-419.

Burns, K. C. 2009: Fine-scale food hoarding decisions in New Zealand robins (Petroica australis): is inter-sexual competition important? J. Ornithol. 150, 321-328.

Burns, K. C. \& Steer, J. 2006: Dominance rank influences food hoarding in New Zealand robins Petroica australis. Ibis 148, 266-272.

Burns, K. C. \& van Horik, J. 2007: Sexual differences in food re-caching by New Zealand robins Petroica australis. J. Avian Biol. 38, 394-398.

Clayton, N. S. 1992: The Ontogeny of Food-Storing and Retrieval in Marsh Tits. Behaviour 122, 11-25.

-. 1994: The role of age and experience in the behavioural development of food-storing and retrieval in marsh tits, Parus palustris. Anim. Behav. 47, 1435-1444.

-. 1995: The neuroethological development of food-storing memory: a case of use it, or lose it! Behavioural Brain Research 70, 95-102.

-. 1996: Development of food-storing and the hippocampus in juvenile marsh tits (Parus palustris). Behavioural Brain Research 74, 153-159. 
-. 1998: Memory and the hippocampus in food-storing birds: a comparative approach. Neuropharmacology 37, 441-452.

Clayton, N. S. \& Dickinson, A. 1998: Episodic-like memory during cache recovery by scrub jays. Nature Publishing Group, London, ROYAUME-UNI.

Clayton, N. S. \& Krebs, J. R. 1994: Memory for spatial and object-specific cues in foodstoring and non-storing birds. Journal of Comparative Physiology A 174, 371-379.

Clayton, N. S., Mellor, R. \& Jackson, A. 1996: Seasonal patterns of food storing in the Jay Garrulus glandarius. Ibis 138, 250-255.

Collopy, M. W. 1977: Food caching by female American kestrels in winter. The Condor 79, 63-68.

Dally, J. M., Clayton, N. S. \& Emery, N. J. 2006: The behaviour and evolution of cache protection and pilferage. Anim. Behav. 72, 13-23.

Dally, J. M., Emery, N. J. \& Clayton, N. S. 2005: Cache protection strategies by western scrub-jays, Aphelocoma californica: implications for social cognition. Anim. Behav. 70, 1251-1263.

-. 2010: Avian Theory of Mind and counter espionage by food-caching western scrub-jays (Aphelocoma californica). Eur. J. Dev. Psychol. 7, 17-37.

Duncan, P. J., Webb, P. I. \& Palmeirim, J. M. 1999: Distribution of New Zealand robins within a forest mosaic. Emu 99, 222-226.

Emery, N. J. 2006: Cognitive Ornithology: The Evolution of Avian Intelligence. Philosophical Transactions: Biological Sciences 361, 23-43.

Emery, N. J. \& Clayton, N. S. 2001: Effects of experience and social context on prospective caching strategies by scrub jays. Nature 414, 443-446.

-. 2004: The Mentality of Crows: Convergent Evolution of Intelligence in Corvids and Apes. Science 306, 1903-1907.

-. 2009: Comparative Social Cognition. Annu. Rev. Psychol. 60, 87-113.

Emmerton, J. 2001: Birds' Judgments of Number and Quantity. In: Avian Visual Cognition. (Cook, R. G., ed). Comparative Cognition Press.

Feigenson, L., Dehaene, S. \& Spelke, E. 2004: Core systems of number. Trends in Cognitive Sciences 8, 307-314.

Galea, L. A. M., Kavaliers, M., Ossenkopp, K. P., Innes, D. \& Hargreaves, E. L. 1994: Sexually dimorphic spatial learning varies seasonally in two populations of deer mice. Brain Research 635, 18-26.

Gerber, L. R., Reichman, O. J. \& Roughgarden, J. 2004: Food hoarding: future value in optimal foraging decisions. Ecological Modelling 175, 77-85. 
Gould-Beierle, K. L. \& Kamil, A. C. 1998: Use of Landmarks in Three Species of Foodstoring Corvids. Ethology 104, 361-377.

Gresack, J. E. \& Frick, K. M. 2003: Male mice exhibit better spatial working and reference memory than females in a water-escape radial arm maze task. Brain Research 982, 98107.

Hauser, M. D., Carey, S. \& Hauser, L. B. 2000: Spontaneous number representation in semifree-ranging rhesus monkeys. Proceedings of the Royal Society of London. Series B: Biological Sciences 267, 829-833.

Hay, O. P. 1887: The Red-Headed woodpecker a hoarder. The Auk 4, 193-196.

Healy, S. D., Bacon, I. E., Haggis, O., Harris, A. P. \& Kelley, L. A. 2009: Explanations for variation in cognitive ability: Behavioural ecology meets comparative cognition. Behavioural Processes 80, 288-294.

Healy, S. D., de Kort, S. R. \& Clayton, N. S. 2005: The hippocampus, spatial memory and food hoarding: a puzzle revisited. TRENDS in Ecology and Evolution 20, 17-22.

Heinrich, B. \& Pepper, J. W. 1998: Influence of competitors on caching behaviour in the common raven,Corvus corax. Anim. Behav. 56, 1083-1090.

Herz, R. S., Zanette, L. \& Sherry, D. F. 1994: Spatial cues for cache retrieval by blackcapped chickadees. Anim. Behav. 48, 343-351.

Hitchcock, C. L. \& Sherry, D. F. 1990: Long-term memory for cache sites in the blackcapped chickadee. Anim. Behav. 40, 701-712.

-. 1995: Cache pilfering and its prevention in pairs of black-capped chickadees. J. Avian Biol. 26, 187-192.

Holdaway, R. N., Worthy, T. H. \& Tennyson, A. J. D. 2001: A working list of breeding bird species of the New Zealand region at first human contact. New Zealand Journal of Zoology 28, 119-187.

Holthuijzen, A. M. A. 1990: Prey delivery, caching, and retrieval rates in nesting Prairie Falcons. The Condor 92, 475-484.

Hunt, S., Low, J. \& Burns, K. C. 2008: Adaptive numerical competency in a food-hoarding songbird. Proc. R. Soc. B-Biol. Sci. 275, 2373-2379.

Jones, C. M., Braithwaite, V. A. \& Healy, S. D. 2003: The evolution of sex differences in spatial ability. Behav. Neurosci. 117, 403-411.

Kamil, A. C. \& Balda, R. P. 1985: Cache recovery and spatial memory in Clark's Nutcrackers (Nucifraga columbiana). Journal of Experimental Psychology 11, 95-111.

Kamil, A. C., Balda, R. P. \& Good, S. 1999: Patterns of movement and orientation during caching and recovery by Clark's nutcrackers, Nucifraga columbiana. Anim. Behav. 57, 1327-1335. 
Kamil, A. C., Goodyear, A. J. \& Cheng, K. 2001: The Use of Landmarks by Clark's Nutcrackers: First Tests of a New Model. The Journal of Navigation 54, 429-435.

Kamil, A. C. \& Gould, K. L. 2008: Memory in Food Caching Animals. In: Learning and Memory: A Comprehensive Reference. (Manzel, R. \& Bryne, J. H., eds). Elsevier, Amsterdam. pp. 419-439.

Kavaliers, M., Ossenkopp, K. P., Galea, L. A. M. \& Kolb, B. 1998: Sex differences in spatial learning and prefrontal and parietal cortical dendritic morphology in the meadow vole, Microtus pennsylvanicus. Brain Research 810, 41-47.

Korpimaki, E. 1987: Prey caching of breeding Tengmalm's Owls Aegolius funereus as a buffer against temporary food shortage. Ibis 129, 499-510.

Krebs, J. R., Clayton, N. S., Healy, S. D., Cristol, D. A., Patel, S. N. \& Jolliffe, A. R. 1996: The ecology of the avian brain: food-storing memory and the hippocampus. Ibis 138, $34-46$.

Low, J., Burns, K. C. \& Hauber, M. E. 2009: Wild number sense in brood parasitic Brownheaded cowbirds. Ibis 151, 775-777.

Lundborg, K. \& Brodin, A. 2003: The effect of dominance rank on fat deposition and food hoarding in the Willow Tit Parus montanus- an experimental test. Ibis 145, 78-82.

Lyon, B. E. 2003: Egg recognition and counting reduce costs of avian conspecific brood parasitism. Nature 422, 495-499.

Macleod, R., Barnett, P., Clark, J. A. \& Cresswell, W. 2005: Body mass change strategies in blackbirds Turdus merula: the starvation-predation risk trade-off. Journal of Animal Ecology 74, 292-302.

MacRoberts, M. H. 1975: Food storage and winter territory in Red-Headed woodpeckers in Northwestern Louisiana. The Auk 92, 382-385.

Maguire, E. A., Burgess, N. \& O'Keefe, J. 1999: Human spatial navigation: cognitive maps, sexual dimorphism, and neural substrates. Current Opinion in Neurobiology 9, 171-177.

McGavin, S. 2009: Density and pair fidelity in a translocated population of North Island robin (Petroica longipes). Notornis 56, 206-212.

McNamara, J. M., Houston, A. I. \& Krebs, J. R. 1990: Why hoard? The economics of food storing in tits, Parus spp. Behavioral Ecology 1, 12-23.

Menzies, I. J. \& Burns, K. C. 2008: Food hoarding in the New Zealand robins: A review and synthesis. In: Animal Behaviour: New Research. (Weber, E. A. \& Krause, L. H., eds). Nova Science Publishers, Inc. pp. $163-183$.

-. 2010: Temporal shifts in the pair-bond dynamics of New Zealand robins (Petroica australis). N. Z. J. Ecol. 34. 
Miller, H. C. \& Lambert, D. M. 2006: A molecular phylogeny of New Zealand's Petroica (Aves : Petroicidae) species based on mitochondrial DNA sequences. Molecular Phylogenetics and Evolution 40, 844-855.

Miskelly, C., Empson, R. \& Wright, K. 2005: Forest birds recolonising Wellington. Notornis 52, 21-26.

O'Keefe, J. \& Nadel, L. 1979: The hippocampus as a cognitive map. Behav. Brain Sci. 2, 520-528.

Pepperberg, I. 2006: Grey parrot numerical competence: a review. Anim. Cogn. 9, 377-391.

Powlesland, R. G. 1980: Food storing behavior of the South Island New Zealand robin Petroica australis australis. Mauri Ora 8, 11-20.

-. 1981a: Comparison of time-budgets for mainland and outer Chetwode Island populations of adult male South Island robins. N. Z. J. Ecol. 4, 98-105.

-. 1981b: The foraging behaviour of the South Island robin Petroica australis australis. Notornis 28, 89-102.

-. 1997: Protocols for monitoring New Zealand robins (Petroica australis). Department of Conservation.

Powlesland, R. G., Knegtmans, J. W. \& Marshall, I. S. J. 2000: Breeding biology of North Island Robins (Petroica australis longipes) in Pureora Forest Park. Notornis 47, 97-195.

Pravosudov, V. V. 2006: On seasonality in food-storing behaviour in parids: do we know the whole story? Anim. Behav. 71, 1455-1460.

Pravosudov, V. V. \& Clayton, N. S. 2002: A test of the adaptive specialization hypothesis: population differences in caching, memory, and the hippocampus in Black-capped Chickadees (Poecile atricapilla). Behav. Neurosci. 116, 515-522.

Rinderer, T. E. \& Baxter, J. R. 1979: Honey bee hoarding behaviour: Effects of previous stimulation by empty comb. Anim. Behav. 27, 426-428.

Rinderer, T. E., Bolten, A. B., Harbo, J. R. \& Collins, A. M. 1982: Hoarding behavior of european and africanized honey bees (Hymenoptera: Apidae) Journal of Economic Entomology 75.

Rumbaugh, D. M., Savage-Rumbaugh, S. \& Hegel, M. T. 1987: Summation in the chimpanzee (Pan troglodytes). Journal of Experimental Psychology: Animal Behavior Processes 13, 107-115.

Scheid, C. \& Bugnyar, T. 2008: Short-term observational spatial memory in Jackdaws (Corvus monedula) and Ravens (Corvus corax). Anim. Cogn. 11, 691-698.

Sherry, D. 1984: Food storage by black-capped chickadees: Memory for the location and contents of caches. Anim. Behav. 32, 451-464. 
-. 1992: Landmarks, the Hippocampus, aand Spatial Search in Food-Storing Birds. In: Cognitive Aspects of Stimulus Control. (Honig, W. K. \& Fetterman, J. G., eds). Lawrence Erlbaum Associates, Inc., Hillsdale. pp. 185-201.

Sherry, D. F. 1998: The ecology and neurobiology of spatial memory. In: Cognitive Ecology. (Dukas, R., ed). The University of Chicago Press, Chicago.

Sherry, D. F., Krebs, J. R. \& Cowie, R. J. 1981: Memory for the location of stored food in marsh tits. Anim. Behav. 29, 1260-1266.

Sherry, D. F. \& Vaccarino, A. L. 1989: Hippocampus and memory for food caches in blackcapped chickadees. Behav. Neurosci. 103, 308-318.

Shettleworth, S. J. 1990: Spatial memory in food-storing birds. Philosophical Transactions: Biological Sciences 329, 143-151.

Shettleworth, S. J. \& Hampton, R. R. 1998: Adaptive specializations of spatial cognition in food-storing birds? Approaches to testing a comparative hypothesis. In: Animal cognition in nature: the convergence of psychology and biology in laboratory and field. (Balda, R. P., Pepperberg, I. M. \& Kamil, A. C., eds). Academic Press, San Diego, California.

Shettleworth, S. J., Hampton, R. R. \& Westwood, R. P. 1995: Effects of season and photoperiod on food storing by black-capped chickadees, Parus atricapillus. Anim. Behav. 49, 989-998.

Shettleworth, S. J. \& Krebs, J. R. 1986: Stored and encountered seeds: A comparison of two spatial memory tasks in marsh tits and chickadees. Journal of Experimental Psychology: Animal Behavior Processes 12, 248-257.

Smith, C. C. \& Reichman, O. J. 1984: The evolution of food caching by birds and mammals. Annual Review of Ecology and Systematics 15, 329-351.

Smulders, T. V., Gould, K. L. \& Leaver, L. A. 2010: Using ecology to guide the study of cognitive and neural mechanisms of different aspects of spatial memory in foodhoarding animals. Philos. Trans. R. Soc. B-Biol. Sci. 365, 883-900.

Smulders, T. V., Sasson, A. D. \& DeVoogd, T. J. 1995: Seasonal variation in hippocampal volume in a food-storing bird, the black-capped chickadee. Wiley Subscription Services, Inc., A Wiley Company. pp. 15-25.

Smulders, T. V., Shiflett, M. W., Sperling, A. J. \& DeVoogd, T. J. 2000: Seasonal changes in neuron numbers in the hippocampal formation of a food-hoarding bird: The blackcapped chickadee. Journal of Neurobiology 44, 414-422.

Stacey, P. B. 1981: Foraging behavior of the Acorn woodpecker in Belize, Central America. The Condor 83, 336-339.

Steer, J. \& Burns, K. C. 2008: Seasonal variation in male-female competition, cooperation and selfish hoarding in a monogamous songbird. Behav. Ecol. Sociobiol. 62, 1175-1183. 
Steer, J. \& van Horik, J. 2006: North Island robin (Petroica australis longipes) food caches are stolen by stitchbirds (Notiomystis cincta) and bellbirds (Anthornis melanura). Notornis 53, 315-316.

Steer, J. E. S. 2006: Seasonality of food use and caching in New Zealand Robins (Petroica australis).Master of Science Thesis, Victoria University of Wellington.

Steffens, K. E., Seddon, P. J., Mathieu, R. \& Jamieson, I. G. 2005: Habitat selection by South Island saddlebacks and Stewart Island robins reintroduced to Ulva Island. N. Z. J. Ecol. 29, 221-229.

Suhonen, J., Halonen, M., Mappes, T. \& Korpimaki, E. 2007: Interspecific competition limits larders of pygmy owls Glaucidium passerinum. J. Avian Biol. 38, 630-634.

Taylor, S. S., Boessenkool, S. \& Jamieson, I. G. 2008: Genetic monogamy in two long-lived New Zealand passerines. J. Avian Biol. 39, 579-583.

Tomback, D. F. 1980: How nutcrackers find their seed stores. The Condor 82, 10-19.

Tomonaga, M. 2008: Relative numerosity discrimination by chimpanzees (Pan troglodytes): evidence for approximate numerical representations. Anim. Cogn. 11, 43-57.

Trick, L. M. \& Pylyshyn, Z. W. 1994: Why are small and large numbers enumerated differently? A limited-capacity preattentive stage in vision. Psychological Review 101, 80-102.

Uller, C., Jaeger, R., Guidry, G. \& Martin, C. 2003: Salamanders (Plethodon cinereus) go for more: rudiments of number in an amphibian. Anim. Cogn. 6, 105-112.

van Horik, J. \& Burns, K. C. 2007: Cache spacing patterns and reciprocal cache theft in New Zealand robins. Anim. Behav. 73, 1043-1049.

Vander Wall, S. B. 1982: An experimental analysis of cache recovery in Clark's nutcracker. Animal Behaviour 30, 84-94.

-. 1990: Food Hoarding in Animals. Chicago University Press, Chicago, IL.

Vander Wall, S. B. \& Jenkins, S. H. 2003: Reciprocal pilferage and the evolution of foodhoarding behavior. Behavioral Ecology 14, 656-667.

Watanabe, S. \& Clayton, N. S. 2007: Observational visuospatial encoding of the cache locations of others by western scrub-jays (Aphelocoma californica). J. Ethol. 25, 271279.

White, D. J., Ho, L. \& Freed-Brown, G. 2009: Counting chicks before they hatch: Female cowbirds can time readiness of a host nest for parasitism. Psychological Science 20, 1140-1145.

Witter, M. S., Cuthill, I. C. \& Bonser, R. H. C. 1994: Experimental investigations of massdependent predation risk in the European starling, Sturnus vulgaris. Anim. Behav. 48, 201-222. 
Wood, M. D. 1993: The Effect of Profitability on Caching by the Eastern Chipmunk (Tamias striatus). American Midland Naturalist 129, 139-144. 